\title{
International veterinary epilepsy task force recommendations for systematic sampling and processing of brains from epileptic dogs and cats
}

\author{
Kaspar Matiasek ${ }^{1 *}$, Martí Pumarola i Batlle², Marco Rosati ${ }^{1}$, Francisco Fernández-Flores², Andrea Fischer ${ }^{3}$, \\ Eva Wagner ${ }^{1}$, Mette Berendt ${ }^{3}$, Sofie F. M. Bhatti ${ }^{4}$, Luisa De Risio ${ }^{5}$, Robyn G. Farquhar ${ }^{6}$, Sam Long ${ }^{7}$, Karen Muñana ${ }^{8}$, \\ Edward E. Patterson ${ }^{9}$, Akos Pakozdy $^{10}$, Jacques Penderis ${ }^{11}$, Simon Platt ${ }^{12}$, Michael Podell ${ }^{13}$, Heidrun Potschka ${ }^{14}$, \\ Clare Rusbridge ${ }^{15,16}$, Veronika M. Stein ${ }^{17}$, Andrea Tipold ${ }^{17}$ and Holger A. Volk ${ }^{18}$
}

\begin{abstract}
Traditionally, histological investigations of the epileptic brain are required to identify epileptogenic brain lesions, to evaluate the impact of seizure activity, to search for mechanisms of drug-resistance and to look for comorbidities. For many instances, however, neuropathological studies fail to add substantial data on patients with complete clinical work-up. This may be due to sparse training in epilepsy pathology and or due to lack of neuropathological guidelines for companion animals.

The protocols introduced herein shall facilitate systematic sampling and processing of epileptic brains and therefore increase the efficacy, reliability and reproducibility of morphological studies in animals suffering from seizures. Brain dissection protocols of two neuropathological centres with research focus in epilepsy have been optimised with regards to their diagnostic yield and accuracy, their practicability and their feasibility concerning clinical research requirements.

The recommended guidelines allow for easy, standardised and ubiquitous collection of brain regions, relevant for seizure generation. Tissues harvested the prescribed way will increase the diagnostic efficacy and provide reliable material for scientific investigations.
\end{abstract}

Keywords: Canine, Feline, Seizures, Hippocampus, Ictogenic, Epileptogenic, Processing, Neuropathology

\section{Background}

Paroxysmal seizure-like events are one of the most common causes of admission to neurological services in small animal practice. With a prevalence ranging between $0.5 \%$ and $5.0 \%$ amongst a general non-referral population of dogs, with higher number of dogs being affected in specific breeds [1-4], epilepsy is a major health issue that severely affects the performance, cognition and behaviour of pets with recurrent seizures and thereby the quality of life of the animals and owners, the owners' economy as well as their range of social activities [5-7].

\footnotetext{
* Correspondence: kaspar.matiasek@neuropathologie.de

'Section of Clinical and Comparative Neuropathology, Centre for Clinical Veterinary Medicine, Ludwig-Maximilians-University, Veterinärstr. 13, 80539 Munich, Germany

Full list of author information is available at the end of the article
}

Hence, the clinical and socioeconomical impact of epilepsy, more than its semiological and pathomechanistic resemblance to human epilepsy has been a trigger of clinical research in that field ever since. However, the most recent advances of imaging, video electroencephalography and telemetry, pharmacotherapy and neurogenetics kickedoff a new wave of enthusiasm in epileptology amongst veterinary neurologists $[1,8-13]$.

With some exceptions [14, 15], the pace of clinical achievements in diagnostics, classification and management of epilepsy patients in veterinary practice has not been paralleled by comparable insights into epilepsy-associated tissue changes and, in particular, those underlying drug resistance.

Brain tissue studies in clinically affected animals often are anecdotal and rarely comprise investigations for causative changes and biomarkers. If tissue studies represent the mainstay of rodent models of epilepsy, research in 
Table 1 Skill level thresholds in brain pathology with special reference to epilepsy pathology

\begin{tabular}{|c|c|c|c|c|c|}
\hline Level & Experience & Anatomical baseline skills & $\begin{array}{l}\text { Semiological baseline } \\
\text { skills \& clinical } \\
\text { neurolocalisation }\end{array}$ & Neuropathology baseline skills & Achievement \\
\hline \multirow[t]{3}{*}{0} & None: & \multirow[t]{3}{*}{ none } & \multirow[t]{3}{*}{ none } & \multirow[t]{3}{*}{ none } & \multirow[t]{3}{*}{ n.a. } \\
\hline & $\begin{array}{l}1^{\text {st }} \text { year student } \\
\text { (veterinary \& human } \\
\text { medicine, neurobiology) }\end{array}$ & & & & \\
\hline & Untrained technician & & & & \\
\hline \multirow[t]{5}{*}{ I } & & \multirow{4}{*}{$\begin{array}{l}\text { External: Recognition of cerebrum, } \\
\text { cerebellum, brain stem and } \\
\text { frontal/parietal/temporal/ } \\
\text { occipital regions. }\end{array}$} & & & \\
\hline & Basic: & & \multirow{4}{*}{$\begin{array}{l}\text { Distinction of clinical forebrain, } \\
\text { cerebellar and brainstem signs. }\end{array}$} & \multirow{3}{*}{$\begin{array}{l}\text { Macro: Spotting malacia, gross } \\
\text { malformations, mass } \\
\text { lesions, haemorrhage. }\end{array}$} & \multirow{4}{*}{$\begin{array}{l}\text { Easy, } \\
\text { Single training, } \\
\text { Within weeks }\end{array}$} \\
\hline & $2^{\text {nd }}$ year student, & & & & \\
\hline & Irained technician & & & & \\
\hline & & Internal: Distinction of white vs grey matter. & & Micro: None to basic neurohistology. & \\
\hline \multirow[t]{5}{*}{$\|$} & & & & & \\
\hline & Advanced: & \multirow{4}{*}{$\begin{array}{l}\text { Recognition of brain lobes, major } \\
\text { brain regions (e.g. hippocampus } \\
\text { thalamus, basal nuclei), tracts and } \\
\text { of regions containing expected nuclei. }\end{array}$} & \multirow{3}{*}{$\begin{array}{l}\text { General: Specific neurolocalisation } \\
\text { based } \\
\text { on clinical signs. }\end{array}$} & \multirow{3}{*}{$\begin{array}{l}\text { General: Recognition of basic } \\
\text { malformations, mass effects, } \\
\text { haemorrhage, infiltrative lesions } \\
\text { and basic neurodegeneration. }\end{array}$} & \multirow{4}{*}{$\begin{array}{l}\text { Demanding, } \\
\text { Repeated training } \\
\text { Within months }\end{array}$} \\
\hline & $\begin{array}{l}\text { Pathology \& neurology } \\
\text { residents }\end{array}$ & & & & \\
\hline & PhD students & & & & \\
\hline & General pathologist & & $\begin{array}{l}\text { Epilepsy-specific: Distinction } \\
\text { and localisation of seizure types. }\end{array}$ & $\begin{array}{l}\text { Epilepsy-specific: Histological } \\
\text { recognition of } \\
\text { stereotypic seizure-associated } \\
\text { changes. }\end{array}$ & \\
\hline \multirow[t]{7}{*}{ III } & Expert: & \multirow{7}{*}{$\begin{array}{l}\text { Detailed knowledge of the } \\
\text { species-specific topographic and } \\
\text { functional anatomy of the brain } \\
\text { including gyri and folia } \\
\text { organisation, distinct nuclei, } \\
\text { cortical areas and their patterning } \\
\text { as well as fibre connections, } \\
\text { neurotransmitter maps, cell } \\
\text { markers and the vascularity. }\end{array}$} & \multirow{7}{*}{$\begin{array}{l}\text { Capable of subregional and nuclear } \\
\text { neuro-localisation. }\end{array}$} & \multirow{7}{*}{$\begin{array}{l}\text { Recognition and classification } \\
\text { of the above named entities, } \\
\text { plus of microanomalies, distinct } \\
\text { cytopathologies, brain specific } \\
\text { disease markers and } \\
\text { neurodegenerative disorders. }\end{array}$} & \multirow{7}{*}{$\begin{array}{l}\text { Demanding, } \\
\text { Cont' training, } \\
\text { Within years }\end{array}$} \\
\hline & A. broad-based & & & & \\
\hline & $\begin{array}{l}\text { Neurology-trained } \\
\text { pathologist }\end{array}$ & & & & \\
\hline & Pathology-trained & & & & \\
\hline & neurologist & & & & \\
\hline & B. topic-based & & & & \\
\hline & Neuroscientist & & & & \\
\hline
\end{tabular}


Table 2 Important epilepsy-related brain zones and definitions (adapted from [59])

\begin{tabular}{|c|c|}
\hline Epileptogenic zone & $\begin{array}{l}\text { Region of cortex that can generate epileptic } \\
\text { seizures and removal or disconnection of } \\
\text { which should lead to seizure freedom }\end{array}$ \\
\hline Epileptogenic lesion & $\begin{array}{l}\text { Distinct brain lesion, capable of generating } \\
\text { and sustaining epileptic seizures }\end{array}$ \\
\hline Excitable zone & $\begin{array}{l}\text { Region susceptible to excitation spreading } \\
\text { from a primary focus }\end{array}$ \\
\hline Irritative zone & $\begin{array}{l}\text { Region of cortex that generates interictal } \\
\text { epileptiform discharges on EEG }\end{array}$ \\
\hline Seizure/ictal onset zone & Region where a clinical seizure originates \\
\hline Symptomatogenic zone & $\begin{array}{l}\text { Region of cortex that generates the initial } \\
\text { seizure presentation (signs) }\end{array}$ \\
\hline Functional deficit zone & $\begin{array}{l}\text { Region of cortex that in the interictal period } \\
\text { is clinically and/or electrophysiologically abnormal }\end{array}$ \\
\hline |ctal/postictal changes & Nonspecific tissue changes due to local excitotoxicity \\
\hline
\end{tabular}

veterinary medicine appears to focus mainly on advancing the genetic characterisation and less so on brain pathology and anatomical changes.

One of the drawbacks that impacts negatively on the neuropathological contribution to advancing the field of canine and feline epilepsy is the lack of consensus guidelines for brain sampling, tissue processing, candidate areas, stains and algorithms. Instead, most studies employ empirical and inconsistent sampling modes and algorithms that preclude external reproducibility and therefore limit the scientific impact of the data obtained.

A standardised evaluation of brains from patients with epilepsy should provide the basis for an informed dialogue between clinicians and pathologists, and therefore requires a certain level of confidence and expertise in that specific field (Table 1).

As we learned from the dichotomous evolution of epilepsy pathology in humans, the advancement of surgical therapy specifically promoted research and training in focal epilepsies and produced a diaspora of neuropathologists with exceptional skills in reading biopsies from lobectomy. Some of these diagnosticians influentially contribute to the activities of the International League Against Epilepsy (ILAE) and proved successful in implementing tissue studies to the forefront of epilepsy research [16-21].
In stark contrast, the interest in extra-focal pathologies appears generally limited and attempts to foster retrospective post-mortem analyses in human epileptics are sparse unless driven by forensic aspects [22, 23]. Naturally, in veterinary medicine pathologists most commonly face a post-mortem setting with incomplete data sets but with the fortune of the entire brain being available for examination. Due to paucity of centres with specific expertise in epilepsy pathology, however, a dedicated curriculum is difficult to acquire and experts are not easily at hand for aiding processing and evaluation of clinical cases in loco.

This limitation holds true for human autopsies as well. Most requested post-mortem examinations are conducted either by the coroner or hospital pathologists [23]. There is a general perception that neuropathologists do not necessarily have to be involved into examination of epilepsy cases until histological slides are available [23, 24]. This view bears the risk of missing essential information on the brain as prescriptions for sampling roughly propose guidance by macroscopic changes, which requires a keen eye, or from localising clinical, electrophysiological and/or imaging data, which requires special training [25].

Sending-off animal carcasses or unfixed post-mortem tissues for remote examination by specialists is impractical, expensive and, hence, not feasible. Consequently, a meaningful progress in veterinary epilepsy pathology regarding diagnosis, classification and research can be achieved only if procedures and protocols are broadly available and manageable in a para-clinical setting.

Detailed and standardised descriptions are required in particular for immediate procedures, such as harvesting of the brain, sampling from the fresh brain and fixation that can be carried out by training level 0 personnel (Table 1) but in the same vein may pose essential limits to the adjacent work-up, diagnostic yield and accuracy.

Fixed tissues do not underlie the same time pressures. Hence, investigators may acquire the neuro-anatomical knowledge necessary to sample putatively epileptogenic areas (for definition see Table 2) and those likely to carry secondary changes $[23,24]$ during the fixation period.

Since "the obvious" poses the biggest obstacle to sustaining the diagnostic effort, data on the seizuring brain

Table 3 Neuropathological sampling schemes

\begin{tabular}{|c|c|c|c|c|}
\hline Type & Determinant & Subtype & Reproducibility & Required skill levels \\
\hline \multirow[t]{2}{*}{1} & \multirow[t]{2}{*}{ Evidence } & A: structural (MRl, gross pathology) & Good & $0-1$ \\
\hline & & B: functional/symptomatogenic & Good to fair & $\|-|\||$ \\
\hline \multirow[t]{2}{*}{2} & \multirow[t]{2}{*}{ Systematic } & A: disease-dependent, e.g. epilepsy & Good & $\|$ \\
\hline & & B: disease-independent & Good & । \\
\hline \multirow[t]{2}{*}{3} & \multirow[t]{2}{*}{ Random } & A: systematic (random sampling of distinct regions) & Fair to poor & I \\
\hline & & B: non-systematic & Poor & 0 \\
\hline
\end{tabular}




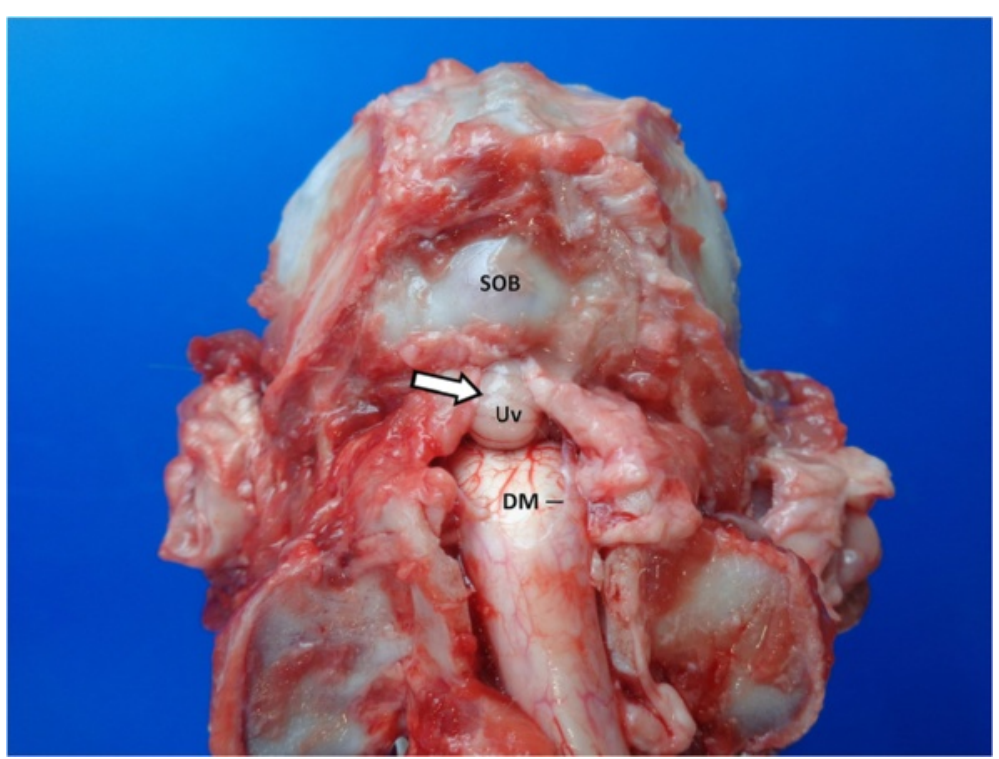

Fig. 1 Caudodorsal view of the ventroflexed craniospinal junction in a dog after removal of paraxial muscles and laminectomie. Note the coning of the cerebellum in the foramen magnum. DM: Dura mater; SOB: supraoccipital bone; Uv: Uvula

are poor in particular for patients with extensive structural brain lesions identified on magnetic resonance imaging (MRI), brain surgery or autopsy. It further needs to be emphasised that the trigger of epilepsy (epileptogenic lesion) and the perilesional brain tissue may not necessarily segregate or be contiguous with the perpetuating epileptogenic zone which becomes evident through incomplete seizure control after lesionectomy [1]. Restriction of the neuropathological examination to these areas, therefore, may not offer an insight into the pathobiology of an epileptic syndrome or the mechanisms of drug resistance.

Even with obvious structural lesions the diagnostician should follow the same procedures and sample the same areas as one would in cases presented with reactive epileptic seizures and idiopathic or genetic epilepsy.

Not to miss relevant information on the nature of seizures, their possible causes and consequences, and on related or unrelated comorbidities, there are three sampling schemes to consider: (1) evidence-based sampling, (2) systematic sampling and, for large brain volumes, (3) random sampling (Table 3).

Scheme 1 comprises two different confidence levels. For obvious reasons, sampling lesions identified via MRI or on gross examination (type 1A) rarely poses a problem. In contrast, symptomatogenic approaches to brain sampling (type 1B) very much rely on both the accuracy of the neurological history (see below) and the clinical understanding of the pathologist. Inexperienced investigators go easily with scheme $1 \mathrm{~A}$ and are inclined to sample brain regions at random (type 3A,B), regardless.
Apart from the above mentioned claim for evidencebased sampling, autopsy guidelines for epilepsy by The Royal College of Pathologists advertise simple and reproducible systematic sampling from cingulate gyrus, hippocampus, parahippocampal gyrus, middle frontal gyrus,

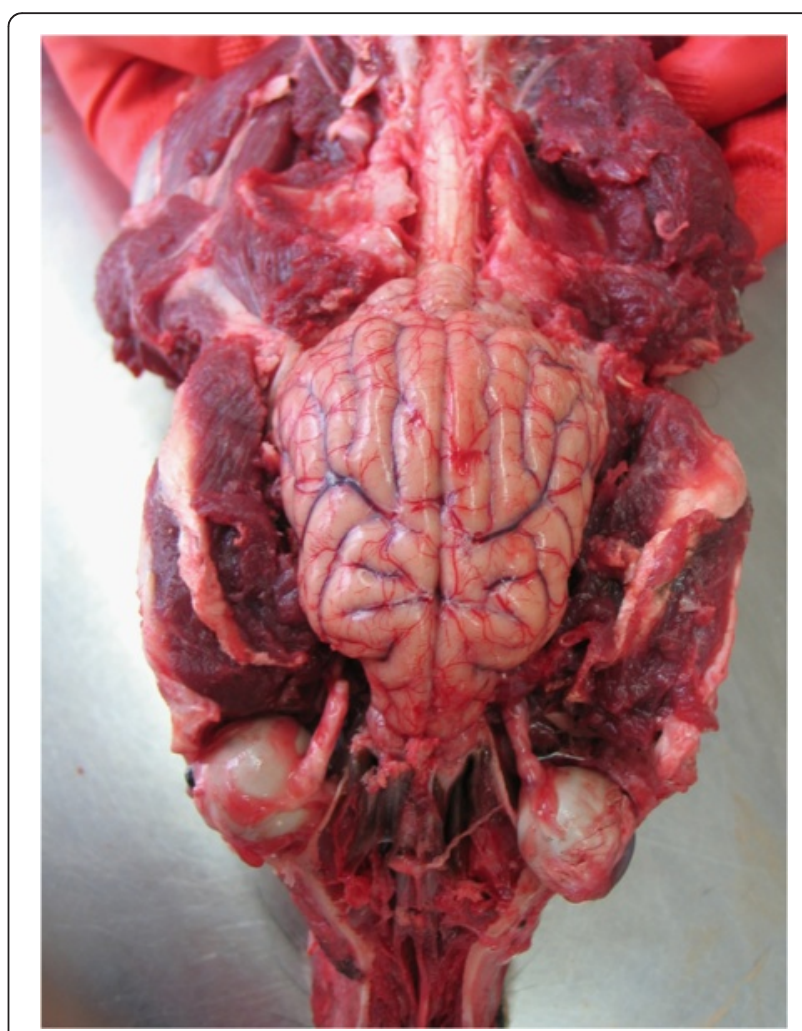

Fig. 2 Canine brain exposed via extensive craniectomy 


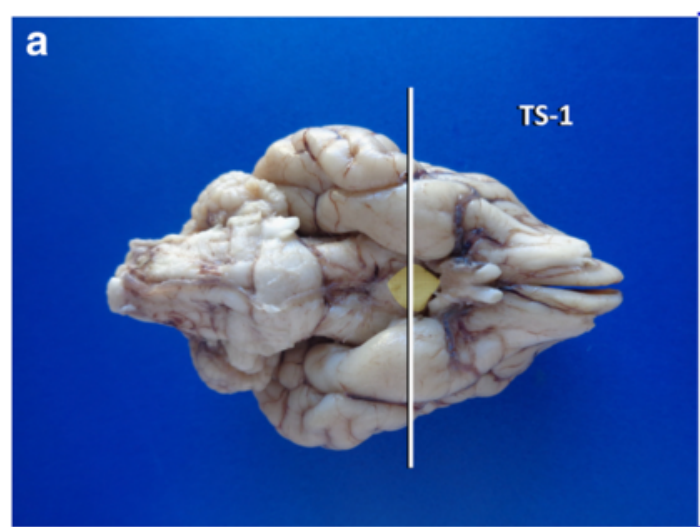

a'

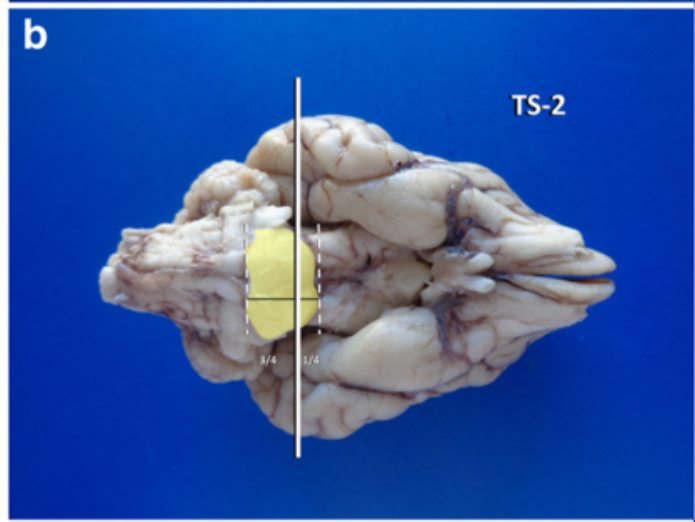

\section{b'}
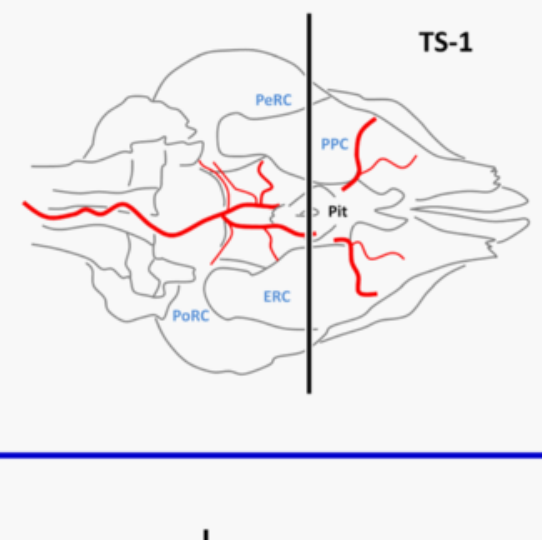

TS-2

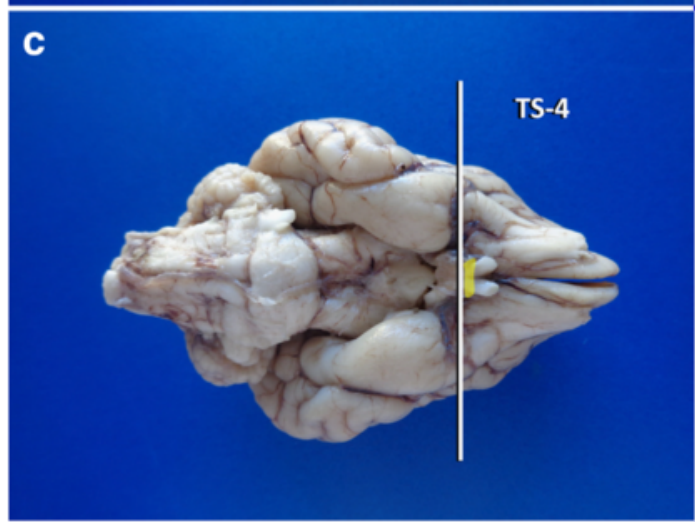

c'
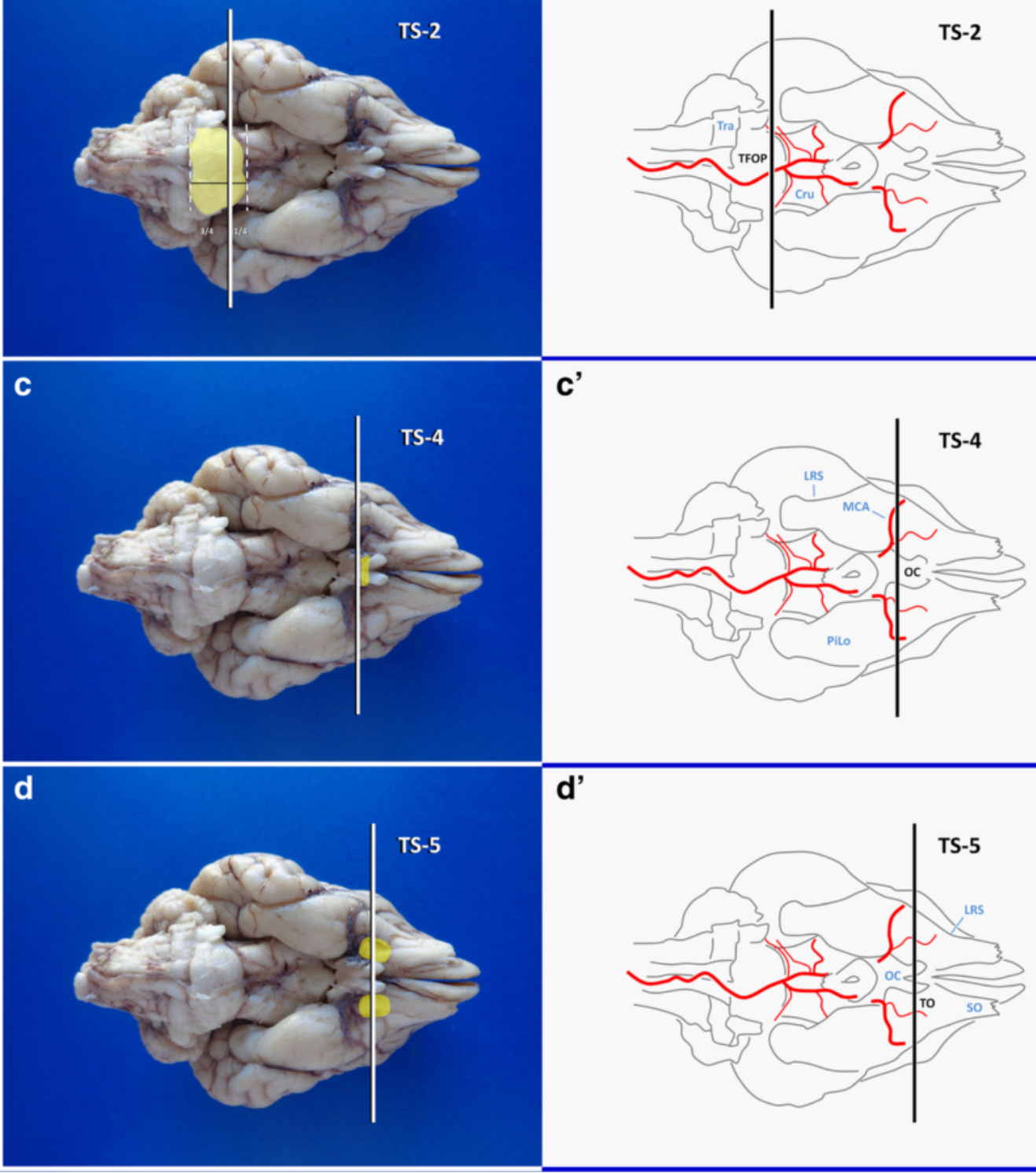

d'

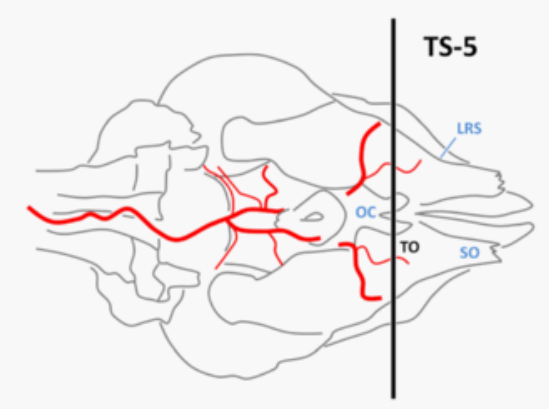

Fig. 3 Landmarks of the ventral brain surface in a dog (Fixed brain $\mathbf{a}, \mathbf{b}, \mathbf{c}, \mathbf{d}$; schematic illustration $\mathbf{a}^{\prime}, \mathbf{b}^{\prime}, \mathbf{c}^{\prime}, \mathbf{d}^{\prime}$ ). Cru: crura cerebri; ERC: entorhinal cortex; LRS: lateral rhinal sulcus; MCA: middle cerebral artery; OC: optic chiasm; PeRC: perirhinal cortex; Pit: pituitary stalk; PiLo: piriform lobe; PoRC: postrhinal cortex; PPC: prepiriform cortex; SO: stria olfactoria; TFOP: transverse fibres of pons; TO: tuberculum olfactorium; Tra: trapezoid body; TS: transverse section 
superior and middle temporal gyri, caudate nucleus, putamen, globus pallidus, cerebellar vermis and cerebellar hemispheres [24]. This selection is based on protocols available for assessment of human neurodegenerative disorders [26] and it is expected to facilitate identification of (1) structural causes of epilepsy; (2) epilepsy-induced changes; and (3) lethal consequences of seizures, such as in Sudden Unexpected Death in Epilepsy (SUDEP) [23]. Likewise, it has been the consensus of the International Veterinary Epilepsy Task Force (IVETF) to encourage and facilitate systematic sampling of epilepsy brains in dogs and cats in order to enable standardised diagnostic approaches and to obtain tissues adequately for epilepsy research. The following protocol thus is driven by both diagnostic motives and neurobiological considerations. We hope, in particular, to facilitate studies on the involvement and role of specific brain regions for seizure propagation and semiology in dogs and cats since our current understanding derives from suspected analogies to human and rodent seizures.
Determination of a structural brain abnormality in epilepsy patients to be considered epileptogenic is based on its type, neuroanatomical localisation and seizure phenomenology. The term "epileptogenic" recently has been restricted to a set of distinctive pathologies (e.g. dysembryoplastic neuroepithelial tumours, focal cortical dysplasia, cavernoma and hippocampal sclerosis). Other pathologies more accurately are referred to as "typically epileptogenic" [2].

The fact that lesionectomy does not necessarily abolish seizures [1] should increase the awareness that the principal lesion may just elicit a process in the excitable cortex that may become an epileptogenic zone or focus itself. The area where discharges convert into clinical seizures is called seizure-onset or ictal-onset zone and may not be contiguous to the symptomatogenic zone, excitation of which determines the clinical type of seizures (Table 2).

In brain surgery of focal epilepsy, the goal is to remove the epileptogenic zone, localised by electroencephalography or functional MRI. The semiology and course,
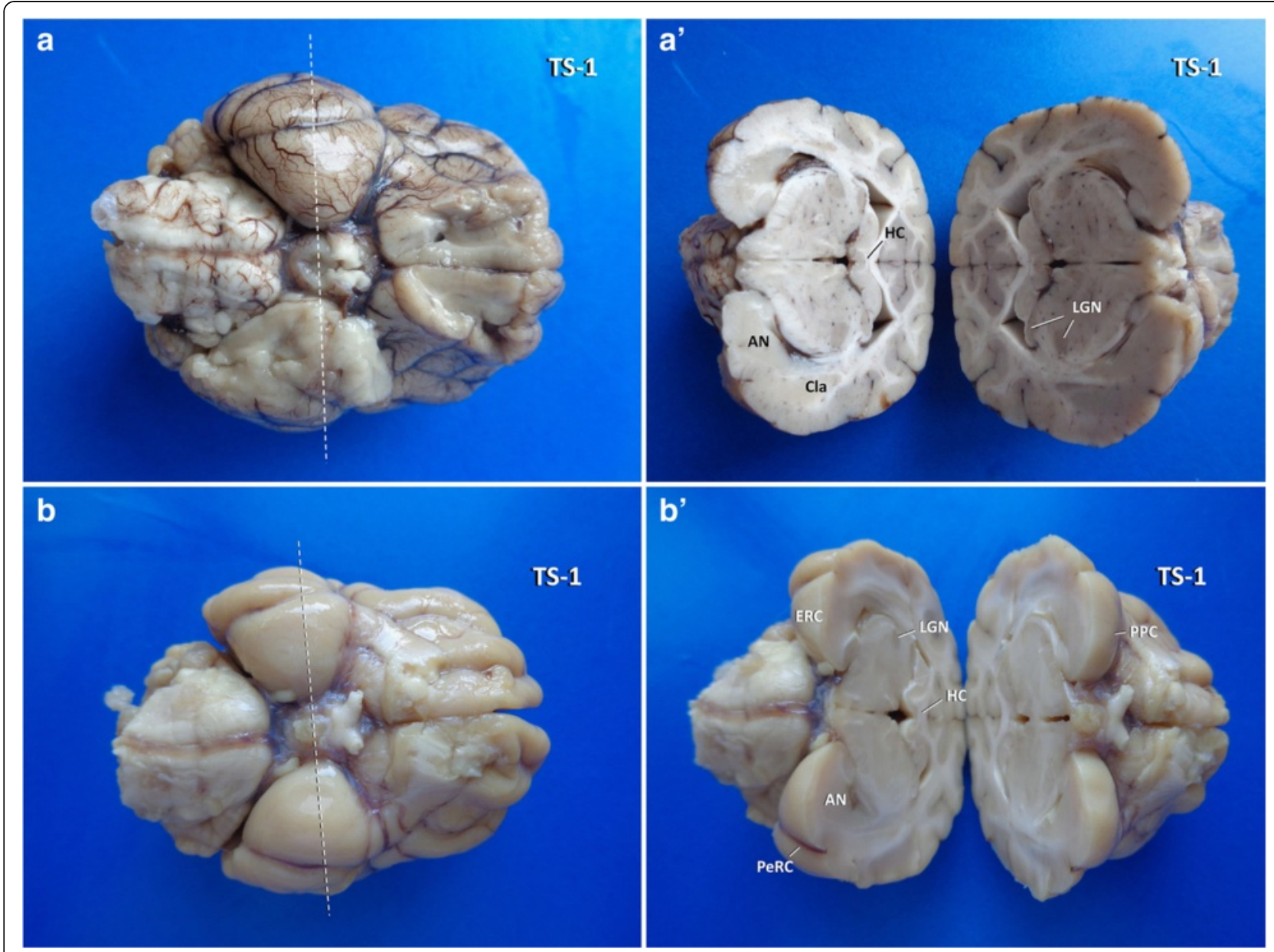

Fig. 4 Insights into the three-dimensional orientation of the hippocampus after TS-1 (dashed line) in dog (a, a') and cat (b, b'). AN: amygdaloid nucleus; Cla: claustrum; ERC: entorhinal cortex; HC: hippocampal commissure; LGN: lateral geniculate nucleus; PeRC: perirhinal cortex; PPC: pre-piriforme cortex 
however, may be influenced by brain regions that act as seizure modifiers (e.g. claustrum) or propagators (e.g. hippocampus). Those regions should not be left unseen, even in straightforward focal structural epilepsy, to enable retrospective pathomechanistic and correlative studies. If the primary or any mirror epileptic focus cannot be excised completely, drug therapy should be continued [1].

With all understanding of required speed and efficacy of post-mortem examination as well as of ubiquitous financial constraints that affect the number of slides which can be processed, complete sampling and tissue banking constitutes the base of good research practice and of future scientific encounters that are expected to impact on the management of epileptic patients.

\section{Short overview of principal candidate areas}

Epilepsy sampling should be guided by the acknowledgment of possible mimicry and overlap with compulsive

Table 4 Macroscopic examination of the unfixed brain

\begin{tabular}{|c|c|c|}
\hline \multicolumn{3}{|c|}{ Unfixed brain—checklist } \\
\hline UB-1 & \multicolumn{2}{|c|}{$\begin{array}{l}\text { Changes to Cerebrum-cerebellum-brainstem size and volume } \\
\text { ratios }\end{array}$} \\
\hline \multirow[t]{5}{*}{ UB-2 } & \multicolumn{2}{|c|}{ Abnormalities of shape and patterning-tissue } \\
\hline & \multicolumn{2}{|l|}{ a. lobes } \\
\hline & \multicolumn{2}{|l|}{ b. lobules } \\
\hline & \multicolumn{2}{|l|}{ c. gyri } \\
\hline & \multicolumn{2}{|l|}{ d. folia } \\
\hline \multirow[t]{4}{*}{ UB-3 } & \multicolumn{2}{|c|}{ Abnormalities of shape and patterning—spaces (FISS) } \\
\hline & \multicolumn{2}{|l|}{ a. fissures } \\
\hline & \multicolumn{2}{|l|}{ b. sulci } \\
\hline & \multicolumn{2}{|c|}{ c. interfolia spaces } \\
\hline \multirow[t]{7}{*}{ UB-4 } & \multicolumn{2}{|c|}{ Meningeal features } \\
\hline & \multirow[t]{2}{*}{ 1. Dura mater } & a. thickness/appearance \\
\hline & & b. venous sinuses \\
\hline & \multirow[t]{4}{*}{ 2. Leptomeninx } & a. transparency \& thickness \\
\hline & & b. meningeal blood vessels \\
\hline & & 1. filling \\
\hline & & 2. pattern \& branching \\
\hline \multirow[t]{6}{*}{ UB-5 } & \multicolumn{2}{|c|}{ Supracollicular features } \\
\hline & \multicolumn{2}{|c|}{ 1. Tentorium cerebelli } \\
\hline & \multicolumn{2}{|c|}{ a. position/impingement } \\
\hline & \multicolumn{2}{|l|}{ b. thickness } \\
\hline & \multicolumn{2}{|c|}{ 2. Perimesencephalic cisterns/rostrocerebellar space } \\
\hline & \multicolumn{2}{|c|}{ 3. Lamina quadrigemina } \\
\hline \multirow[t]{3}{*}{ UB-6 } & \multicolumn{2}{|c|}{ Cranial nerve roots } \\
\hline & \multicolumn{2}{|c|}{ a. appearance } \\
\hline & \multicolumn{2}{|l|}{ b. course } \\
\hline
\end{tabular}

and behavioural disorders, sleep disorders and movement disorders [3, 4]. Sampling therefore extends from the ascending reticular activating system (ARAS), via thalamocortical areas to extrapyramidal motor centres of the forebrain [5]. Little is known yet about the involvement of certain brain regions in distinct forms of canine and feline epilepsy, apart from orofacial seizures in cats [6]. Broad sampling schemes are necessary at this stage to acquire the respective data.

In most species, postictal and epileptogenic changes predominantly involve grey matter of the forebrain [5] and also Purkinje cells laden with glutamatergic synapses $[7,8]$. Neurochemistry and metabolic demands determine the irritability and hence the intrinsic vulnerability to excitotoxicity. Minor local changes may translate into convulsive activity and from there spread to adjacent or remotely connected excitable areas via extra-synaptic migratory excitation or neurotransmission. Certain areas such as frontal cortex and temporal lobe are particularly susceptible to generating and perpetuating seizures and therefore should comprise the main regions of interest when sampling brain tissue $[9,10]$.

Amongst irritable areas, the hippocampus resembles the brain structure most commonly involved in seizures, either primarily or secondarily. Thereby, its involvement

Table 5 Macroscopic examination of the trimmed brain

\begin{tabular}{l}
\hline Trimmed brain-checklist \\
\hline TB-1 $\quad$ ISS base \\
a. depth \\
b. width \\
c. course \\
Cortical ribbon — subcortical white matter \\
a. thickness \\
b. symmetry \\
c. delineation \\
d. white-grey ratio \\
Large white matter tracts, capsules and interposed nuclei \\
a. volume \& ratios \\
b. symmetry \\
c. delineation \\
d. misplaced grey matter \\
Periventricular features \\
a. subependyma/glia limitans interna \\
b. periventricular white matter \\
TB-4
\end{tabular}


goes with essential regional, functional and interspecies differences. In kindled and pilocarpine-treated rats, for example, the ventral hippocampus presents with the earliest discharges and most extensive neuronal losses, amongst the septotemporal hippocampal axis [11, 12]. Likewise the temporoventral body (TVB), is the key area for orofacial seizures amongst temporal lobe epilepsy in cats; it is the main target of limbic encephalitis in humans and cats and it is more susceptible to hippocampal sclerosis (HS) than the dorsal parts of hippocampus [12-15].

HS is defined as pyramidal cell loss with gliosis and resembles one of the most important acquired epilepsypromoting changes in humans [16]. It can result from necrotising and non-necrotising hippocampal lesions and thus should not be used synonymously with hippocampal necrosis. HS is subclassified according to the affected cornu ammonis segments that can be evaluated properly only in perpendicular sections of the hippocampus [17]. Currently, the high prevalence of recurrent feline epilepsy suggests a role in disease propagation in this species [13]. Its occurrence in epileptic dogs awaits further elucidation. Thus, suspected HS from hippocampal scans [18] and volumetry require to be substantiated by tissue studies [19]. Other forms of epilepsy-associated sclerosis occur in entorhinal cortex, amygdala and the subpial molecular layer $[20,21]$. Their occurrence and relevance in feline and canine epilepsy remains to be clarified.

It should be noted that coexistence of HS with other epileptogenic lesions (usually outside of the hippocampus) is called "dual pathology" whereas "double pathology" refers to two epileptogenic principal lesions, other than HS [17]. If the latter occurs together with HS, this situation is referred to as "triple pathology" [22].

Depending on the cause of epilepsy and animal species, the flexure and dorsomedial tip of the hippocampal tail may contribute to the epileptic syndrome. It is important to stick to the perpendicular section throughout the longitudinal (septotemporal) axis of the hippocampus to allow for proper evaluation of the cornu ammonis (CA) segments and the dentate gyrus and for comparison in between the different hippocampal localisations. The same holds true for the subiculum and parahippocampal gyrus that may clarify whether HS is associated with reactive encephalopathy such as in hypoglycaemia [23].

Even though our insights on this topic are incomplete, temporal lobe involvement in canine epilepsy appears to differ greatly from cats [24] and predominantly affects the piriform cortex and amygdala, just rostral to the hippocampal head. Hemispheric transverse sections of the temporal lobe also allow for evaluation of entorhinal, perirhinal and postrhinal cortices, insular cortex and the claustrum, none of which has been systematically investigated in seizuring animals yet.
Table 6 Brain lesion types

\begin{tabular}{lll}
\hline $\begin{array}{l}\text { Pathological lesion } \\
\text { category }\end{array}$ & \multicolumn{2}{l}{ Type \& underlying pathology } \\
\hline PL-1: Discolouration & Pallor & a. oedema \\
& b. gliosis, sclerosis, fibrosis \\
& c. coagulation necrosis \\
& d. mineralisation \\
& e. infiltrative disease \\
& a. oedema \\
& breyish & colliquative necrosis \\
& Yellow & a. pus \\
& b. caseous necrosis \\
& c. nuclear jaundice \\
Brown & a. lipofuscinergic \\
& b. siderosis \\
Black & a. melanin \\
& b. blood \\
Red & blood \\
Pink & carbon monoxide
\end{tabular}

PL-2: Loss \& gain of tissue

Architecture sparing: disproportion \& asymmetry

\begin{tabular}{|c|c|}
\hline \multirow[t]{4}{*}{ 1. Gain } & $\begin{array}{l}\text { a. regional oedema/ } \\
\text { inflammation }\end{array}$ \\
\hline & $\begin{array}{l}\text { b. malformation (e.g } \\
\text { macrogyria) }\end{array}$ \\
\hline & c. harmatoma \\
\hline & d. low grade glioma \\
\hline \multirow[t]{2}{*}{ 2. LosS } & $\begin{array}{l}\text { a. atrophy/ } \\
\text { neurodegeneration }\end{array}$ \\
\hline & b. hypoplasia \\
\hline
\end{tabular}

With architectural changes

$\begin{array}{ll}\text { 1. Gain } & \text { a. oedema } \\ \text { 2. Loss } & \text { b. infiltrative disease } \\ & \text { a. atrophy } \\ \text { b. Topographical } & \text { a. misplacement (e.g. } \\ & \text { heterotopia) } \\ \text { Induration } & \text { b. disorganisation (dysplasia) } \\ & \text { a. glial/sclerosis } \\ & \text { b. neoplasia } \\ & \text { c. fibrosis } \\ \text { Softening } & \text { d. mineralisation } \\ & \text { a. oedema } \\ & \text { b. collequative necrosis } \\ & \text { c. inflammation } \\ \text { d. neoplasia }\end{array}$


Table 7 Systematic trimming of the occipitotemporal region (Block A)

\begin{tabular}{|c|c|c|c|c|c|c|}
\hline$\overline{\text { Cuts }}$ & Time & View/specimen & Landmarks and cutting levels & Orientation of sections & Aim/harvest & Difficulty \\
\hline \multirow[t]{3}{*}{ TS-1 } & \multirow[t]{3}{*}{$0 \mathrm{~min}$} & \multirow{3}{*}{$\begin{array}{l}\text { Ventral view of } \\
\text { whole brain }\end{array}$} & \multirow{3}{*}{$\begin{array}{l}\text { Transverse line through centre of } \\
\text { pituitary stalk and the broadest } \\
\text { laterolateral extension of the } \\
\text { piriform lobe }\end{array}$} & 2D knife axis: laterolateral. & Standard transverse section of the diencephalon. & \multirow[t]{3}{*}{ Easy } \\
\hline & & & & Plane: transverse. & $\begin{array}{l}\text { Exposes the amygdaloid nucleus, thalamus and } \\
\text { often lateral geniculate nucleus, piriform cortex. }\end{array}$ & \\
\hline & & & & Blade movement: ventrodorsal. & $\begin{array}{l}\text { Allows for localisation of rostral tip of hippocampal } \\
\text { tail and head/TVB. }\end{array}$ & \\
\hline \multirow[t]{3}{*}{ TS-2 } & \multirow[t]{3}{*}{$2 \mathrm{~min}$} & \multirow{3}{*}{$\begin{array}{l}\text { Ventral view of } \\
\text { brainstem }\end{array}$} & \multirow{3}{*}{$\begin{array}{l}\text { Transverse line } 2 \mathrm{~mm} \text { caudal to } \\
\text { the rostral border of TFOP }\end{array}$} & 2D knife axis: ventrodorsal. & Standard transverse section of the midbrain. & \multirow[t]{3}{*}{ Easy } \\
\hline & & & & Plane: transverse. & \multirow[t]{2}{*}{ Prerequisite for TVB section } & \\
\hline & & & & Blade movement: laterolateral & & \\
\hline \multirow[t]{3}{*}{ TILT-1 } & \multirow[t]{3}{*}{$4 \mathrm{~min}$} & \multirow{3}{*}{$\begin{array}{l}\text { Caudal view of } \\
\text { occipital lobe } \\
\text { and rostral } \\
\text { mesencephalic } \\
\text { stump }\end{array}$} & \multirow{3}{*}{$\begin{array}{l}\text { Horizontal line just dorsal to } \\
\text { transverse fibres of the pons }\end{array}$} & 2D knife axis: laterolateral. & Epilepsy-specific sections of TVB. & \multirow{3}{*}{$\begin{array}{l}\text { Easy but requires } \\
\text { some practice }\end{array}$} \\
\hline & & & & $\begin{array}{l}\text { Plane: oblique, transverse with rostral } \\
\text { inclination so that the blade cuts the caudal } \\
\text { temporal lobe flexure at right angle. }\end{array}$ & \multirow[t]{2}{*}{ Also shows prepiriform cortex, peri/entorhinal cortex. } & \\
\hline & & & & $\begin{array}{l}\text { Blade movement: from caudoventral to } \\
\text { rostodorsal. }\end{array}$ & & \\
\hline \multirow[t]{3}{*}{ HOR-1 } & \multirow[t]{3}{*}{$7 \mathrm{~min}$} & \multirow[t]{3}{*}{ Same as before } & \multirow{3}{*}{$\begin{array}{l}\text { Horizontal line through the } \\
\text { upper mesencephalic aquaeduct }\end{array}$} & 2D knife axis: laterolateral. & Epilepsy-specific section. & \multirow[t]{3}{*}{ Easy } \\
\hline & & & & Plane: horizontal. & Exposes CV of both hippocampi, parahippocampal & \\
\hline & & & & Blade movement: caudorostral. & $\begin{array}{l}\text { gyri, postrhinal and caudal perirhinal cortex as well } \\
\text { as lateral geniculate nucleus. }\end{array}$ & \\
\hline \multirow[t]{5}{*}{ TILT-2L/R } & \multirow[t]{5}{*}{$9 \min$} & \multirow{5}{*}{$\begin{array}{l}\text { Same as previous } \\
\text { two steps }\end{array}$} & \multirow{5}{*}{$\begin{array}{l}\text { Lines perpendicularly set } \\
\text { through the vertex of both } \\
\text { occipitotemporal flexures. }\end{array}$} & 2D knife axis: & \multirow{3}{*}{$\begin{array}{l}\text { Epilepsy-specific sections of both hippocampal OV } \\
\text { and associated parahippocampal gyri, rostral colliculi, } \\
\text { optic radiations and main visual cortices. }\end{array}$} & \multirow{5}{*}{$\begin{array}{l}\text { Easy but requires } \\
\text { some practice }\end{array}$} \\
\hline & & & & 2R: dextroventral to sinistrodorsal. & & \\
\hline & & & & 2L: sinistroventral to dextrodorsal & & \\
\hline & & & & $\begin{array}{l}\text { Plane: oblique, longitudinal, with lateral } \\
\text { inclination }\left(45^{\circ} \text { and } 135^{\circ}\right) \text {. }\end{array}$ & \multirow[t]{2}{*}{ Also, standard procedure in transtentorial herniation. } & \\
\hline & & & & Blade movement: caudorostral. & & \\
\hline \multirow[t]{3}{*}{ TS-3 } & \multirow[t]{3}{*}{$11 \mathrm{~min}$} & \multirow{3}{*}{$\begin{array}{l}\text { Lateral view of } \\
\text { dorsal wedge } \\
\text { remaining from } \\
\text { tissue Block A }\end{array}$} & \multirow{3}{*}{$\begin{array}{l}\text { Transverse line just } 1-2 \mathrm{~mm} \\
\text { caudal to the level of the } \\
\text { dorsomedial tip of } \\
\text { hippocampus. }\end{array}$} & 2D knife axis: laterolateral. & \multirow{3}{*}{$\begin{array}{l}\text { Epilepsy-specific section of dorsomedial hippocampal } \\
\text { tail and hippocampal commissure, corpus callosum, } \\
\text { occipitomesial cortex including cingulate gyrus and } \\
\text { associated subcortical white matter. }\end{array}$} & \multirow{3}{*}{$\begin{array}{l}\text { Moderately difficult } \\
\text { as the rostrocaudal } \\
\text { range is very small }\end{array}$} \\
\hline & & & & Plane: transverse. & & \\
\hline & & & & $\begin{array}{l}\text { Blade movement: dextrodorsal to } \\
\text { sinistroventral or vice versa. }\end{array}$ & & \\
\hline
\end{tabular}


Being a thalamocortical syndrome, epilepsy frequently affects thalamus and lateral geniculate nucleus (own observations), which is synaptically connected to the occipital cortex. Investigation of this axis also may help to differentiate between primary versus secondary occipital lobe changes, due to forebrain enlargement and impingement by the tentorium cerebelli.

Concerning the rostral pole of the brain, the diagnostic interest in epileptic patients should carry on throughout frontal lobe rostral to lamina terminalis and include the precallosal fronto-olfactory region which is another area with low-threshold excitability.

As the frontal lobe carries the motor cortex and major extrapyramidal motor nuclei, it is the home of nonataxic movement disorders but also resembles an important symptomatogenic zone in motor seizures with stereotypic movement pattern.

Naturally, the plethora of candidate areas for seizure development and perpetuation is intimidating. The good news is, all above mentioned areas and structures are "mutually" sampled by a rather simple trimming protocol within less than $30 \mathrm{~min}$ by inexperienced staff (see Additional file 1) and about $10 \mathrm{~min}$ by experienced investigators. Throughout all levels of expertise, regular consultation of anatomical textbooks and articles featuring topographic brain anatomy is inevitable (for useful examples see [25-28]). Thereby, the examiner needs to be aware of some terminological inconsistencies and the incompleteness of the Nomina Anatomica Veterinaria [27].

\section{Guidelines for brain processing}

Macro dissection and immediate post mortem procedures Removal of the brain in epileptic patients employs a standard approach via removal of the skin and of the muscles of head and neck, mobilisation and dislocation of orbital contents, frontonasal osteotomy and extensive craniectomy. Before further preparation of the atlantooccipital junction, preceding decapitation or supraoccipital osteotomy, attention should be paid to possible cerebellar coning and transforaminal herniation as a consequence to intracranial pressure elevation (Fig. 1) [29].

Upon removal of the calvaria and dorsal (mid sagittal) or ventrolateral (bilateral) durotomy, the exposed brain is inspected in situ (Fig. 2). Thereafter, the olfactory bulbs are explored and mobilised from the cribrosal lamina, the brain is lifted and cranial nerves and the pituitary stalk are transected avoiding unnecessary tearing.

The relief of having extracted the brain in one piece all too often leads to premature immersion in formalin. As a rule, a tiny piece of fresh brain tissue, deriving from a clinically or macroscopically affected target area, should be placed in RNA later (Qiagen Inc, Hilden) or snap-frozen and stored at $-80{ }^{\circ} \mathrm{C}$ for possible molecular analyses. Cerebrospinal fluid, brain swabs for culture and other case-sensitive samples for microbiological and virological testing also require to be harvested from the unfixed brain. If it comes to sampling fresh tissue for an "-omics" approach (genomic, transcriptomic, proteomic, metabolomic) to epilepsy or cryohistology, prefixation sampling protocols can be quite sophisticated

Table 8 Systematic trimming of the frontoparietal region (Block B)

\begin{tabular}{|c|c|c|c|c|c|c|}
\hline Cuts & Time & View/specimen & $\begin{array}{l}\text { Landmarks and cutting } \\
\text { levels }\end{array}$ & Orientation of sections & Aim/harvest & Difficulty \\
\hline \multirow[t]{3}{*}{ TS-4 } & \multirow[t]{3}{*}{$13 \mathrm{~min}$} & \multirow[t]{3}{*}{$\begin{array}{l}\text { Ventral view of the } \\
\text { frontal lobe }\end{array}$} & \multirow[t]{3}{*}{$\begin{array}{l}\text { Transverse line through or } \\
\text { just rostral to optic chiasm }\end{array}$} & 2D knife axis: laterolateral. & $\begin{array}{l}\text { Standard section of the } \\
\text { frontal lobe. }\end{array}$ & \multirow[t]{3}{*}{ Easy } \\
\hline & & & & Plane: transverse. & \multirow{2}{*}{$\begin{array}{l}\text { Boundary between thalamus } \\
\text { and basal nuclei; also shows septal } \\
\text { nuclei, body of fornix, rostral } \\
\text { commissure parietofrontal cortex. }\end{array}$} & \\
\hline & & & & $\begin{array}{l}\text { Blade movement: } \\
\text { ventrodorsal. }\end{array}$ & & \\
\hline \multirow[t]{3}{*}{ TS-5 } & \multirow[t]{3}{*}{$15 \mathrm{~min}$} & \multirow{3}{*}{$\begin{array}{l}\text { Ventral (or dorsal) view } \\
\text { of the frontal lobe }\end{array}$} & \multirow{3}{*}{$\begin{array}{l}\text { Transverse midline section } \\
\text { of olfactory tuberculum }\end{array}$} & 2D knife axis: laterolateral. & \multirow{3}{*}{$\begin{array}{l}\text { Standard section of the frontal lobe } \\
\text { providing the best view of the basal } \\
\text { nuclei and capsules }\end{array}$} & \multirow[t]{3}{*}{ Easy } \\
\hline & & & & Plane: transverse. & & \\
\hline & & & & $\begin{array}{l}\text { Blade movement: } \\
\text { ventrodorsal. }\end{array}$ & & \\
\hline \multirow[t]{3}{*}{ HOR-2 } & \multirow[t]{3}{*}{$17 \mathrm{~min}$} & \multirow{3}{*}{$\begin{array}{l}\text { Rostral view of the } \\
\text { still connected } \\
\text { hemispheres of } \\
\text { olfactoryfrontal brain }\end{array}$} & $\begin{array}{l}\text { 2: Horizontal midline section } \\
\text { through proreus gyrus. }\end{array}$ & 2D knife axis: laterolateral. & $\begin{array}{l}\text { Epilepsy-specific section of the } \\
\text { susceptible olfactoryfrontal cortex. }\end{array}$ & Easy \\
\hline & & & \multirow{2}{*}{$\begin{array}{l}\text { 2',2":..followed by parallel } \\
\text { sections of the ventral block } \\
\text { with } 3 \mathrm{~mm} \text { slice thickness. }\end{array}$} & Plane: horizontal. & \multirow{2}{*}{$\begin{array}{l}\text { Standard section in ethmoidal } \\
\text { pathologies. }\end{array}$} & \\
\hline & & & & $\begin{array}{l}\text { Blade movement: } \\
\text { rostrocaudal. }\end{array}$ & & \\
\hline \multirow[t]{3}{*}{$\mathrm{SAG}-1 \mathrm{~L} / \mathrm{R}$} & \multirow[t]{3}{*}{$19 \min$} & \multirow{3}{*}{$\begin{array}{l}\text { Rostral view of the } \\
\text { dorsal block of the } \\
\text { olfactoryfrontal brain }\end{array}$} & $\begin{array}{l}\text { 1L/R: Sagittal lines through } \\
\text { lateral third of proreus gyrus. }\end{array}$ & 2D knife axis: rostrocaudal. & \multirow[t]{3}{*}{$\begin{array}{l}\text { Epilepsy-specific sections exposing } \\
\text { motor cortex }\end{array}$} & \multirow[t]{3}{*}{ Easy } \\
\hline & & & \multirow{2}{*}{$\begin{array}{l}1 L^{\prime} / R^{\prime} / 1 L^{\prime \prime} / R^{\prime \prime}: . . \text { followed by } \\
\text { parallel sections with } 3 \mathrm{~mm} \\
\text { slice thickness }\end{array}$} & Plane: sagittal. & & \\
\hline & & & & $\begin{array}{l}\text { Blade movement: rostrodorsal } \\
\text { to caudoventral. }\end{array}$ & & \\
\hline
\end{tabular}


and vary in accordance to the objectives of the respective study [30,31].

If sampling is aspired from specific hippocampal regions of the autopsied brain, the dissection protocol mentioned below may apply even though the morphology is preserved better if trimmed after fixation [32]. Detection of pathological changes by less experienced staff increases significantly if gross examination is carried out on the fixed brain [32, 33]

In surgically resected epileptogenic foci, tissue is lamellated and slabs for "omics" and cryohistology are sandwiched in between slices, undergoing routine formalin-fixation and paraffin-embedding (FFPE) [32].

For a standard autopsy setting with an uncertain location of the epileptogenic focus, it still may be worth to snap-freeze a small section of hippocampus. Without risking the accuracy of the standard sections, mentioned below, one single transverse section at the level of infundibular recess of the third ventricle rostral to the mammillary bodies (Figs. 3 and 4) may allow for tissuesparing identification of the dorsomedial tail of the hippocampus from which bilateral samples can easily be taken. Once, this has been achieved, the brain is immersed in a sufficient volume of $10 \%$ neutral buffered formalin and fixed for $48 \mathrm{~h}$ prior to further trimming and gross examination [33].

\section{Post-fixation examination and trimming protocol Preamble}

Sampling of the different aspects of the hippocampus with sections taken perpendicularly to the longitudinal axis of the pyramidal cell band comprises the single most critical step of trimming the epileptic brain.

Nearly all other regions can be retrospectively collected and identified from fixed and trimmed pieces of brain ("bits in a bottle"). A reliable investigation of the

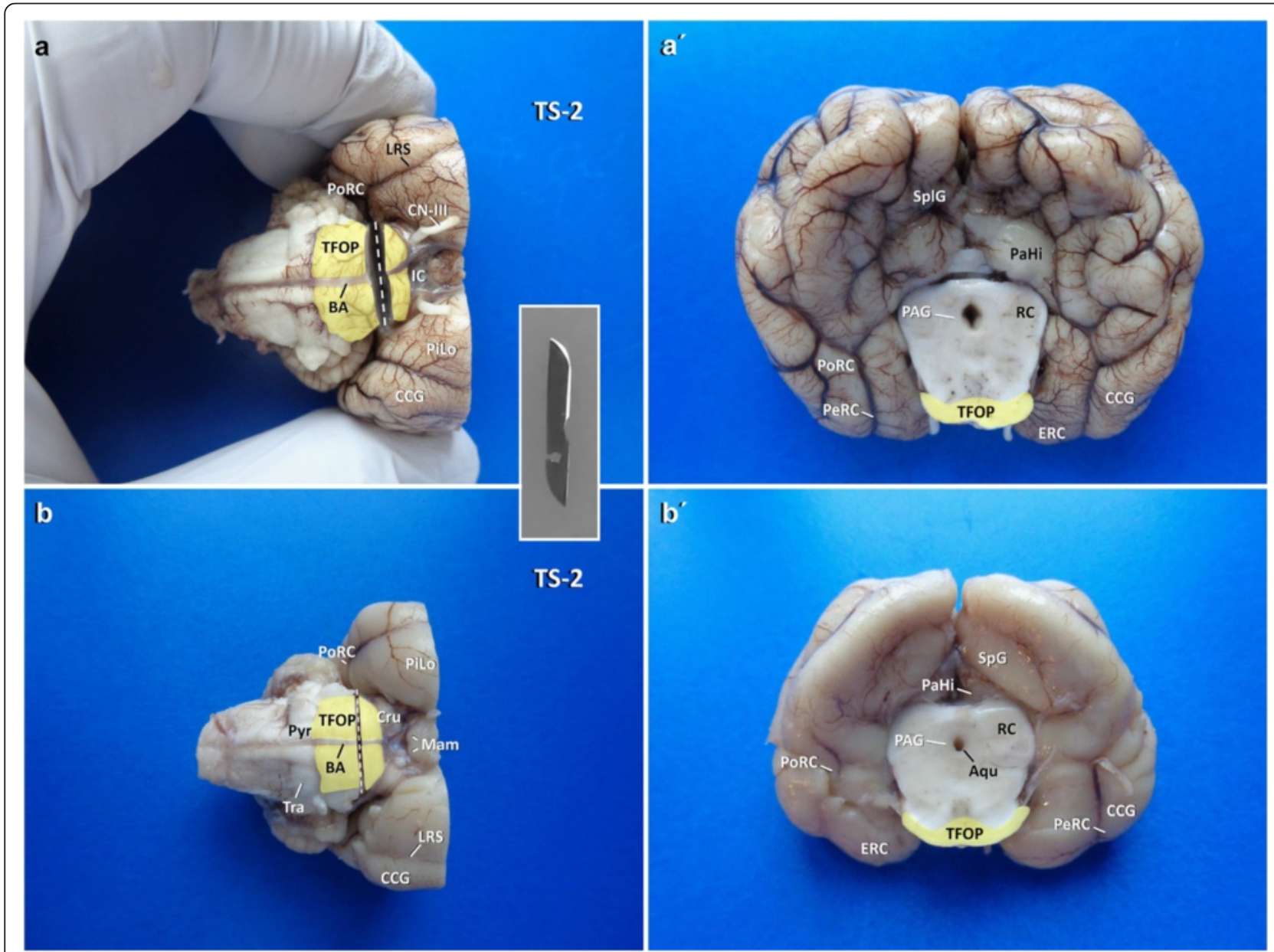

Fig. 5 Planning of TS-2 (a, b) and inspection of the occipitotemporal brain and mesencephalon (a', b') in dog (a', a') and cat (b, b'). Transection is performed by a tipped blade (inlet). Aqu: mesencephalic aqueduct; BA: basilar artery; CCG: caudal composite gyrus; CN-III: cranial nerve III; Cru: crura cerebri; IF: intercrural cistern; LRS: lateral rhinal sulcus; Mam: mammillary bodies; PAG: periaqueductal gray matter; ParaH: parahippocampal gyrus; PeRC: perirhinal cortex; PiLo: piriform lobe; PoRC: postrhinal cortex; Pyr: pyramis. RC: rostral colliculus; SplG: splenial gyrus; TFOP: transverse fibres of pons; Tra: trapezoid body 
hippocampus, however, requires both the correct angle of section and its physical connection to adjacent and connected structures such as the parahippocampal gyrus. Thus, hippocampal sampling represents the centre of efforts at this stage. However, the brain should not be cut without prior evaluation! Essential information may be missed and irreplaceably lost if macroscopic examination has been skipped.

As in a general setting, the brain should be constantly evaluated for anatomical abnormalities (Tables 4 and 5) and distinct lesions (Table 6). Concerning the untrimmed brain (Tables 4), this in particular refers to

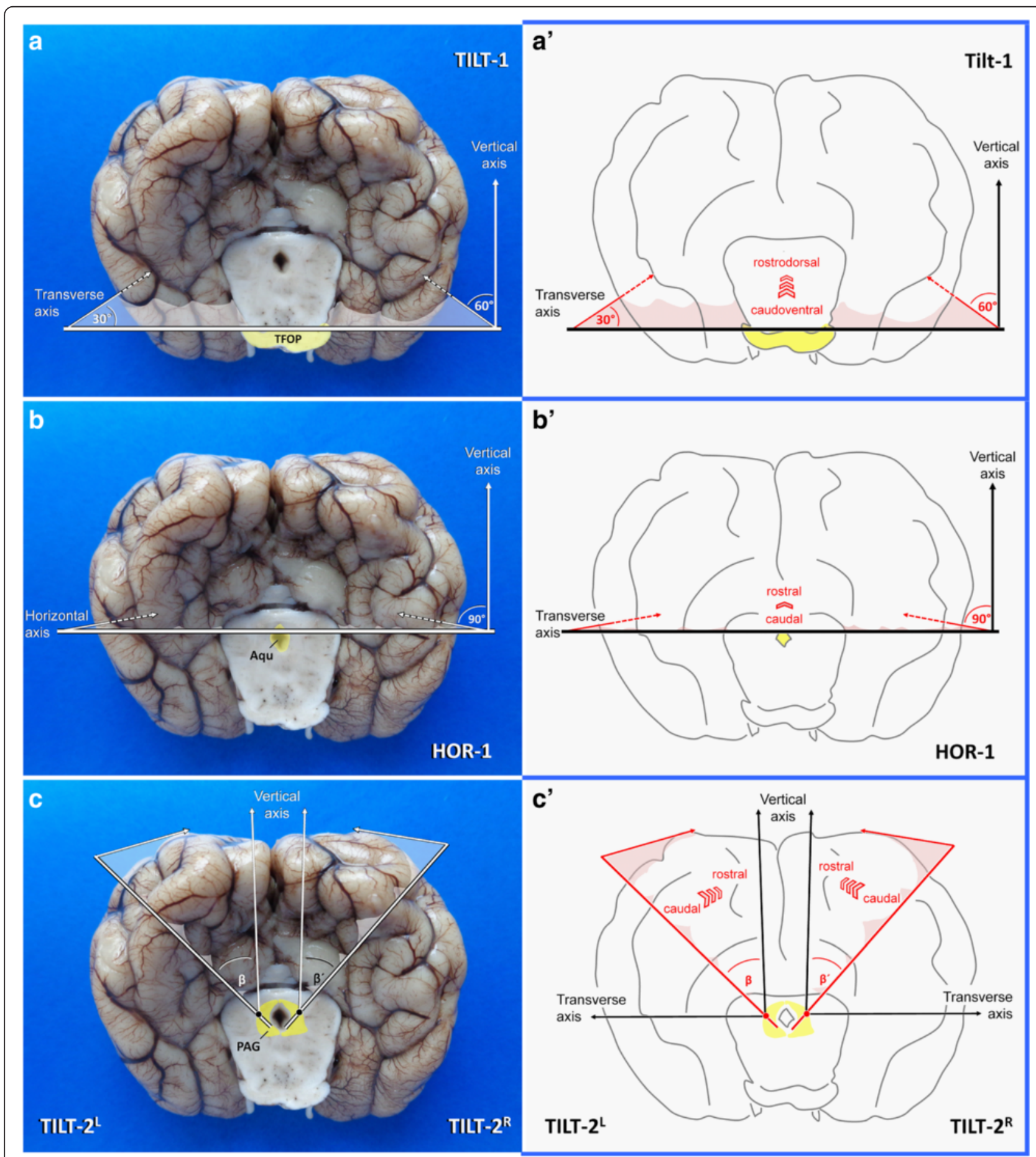

Fig. 6 Planning of occipitotemporal brain dissection in three steps. TFOP: transverse fibres of pons; Aqu: mesencephalic aqueduct; PAG: periaqueductal gray matter. Canine brain 


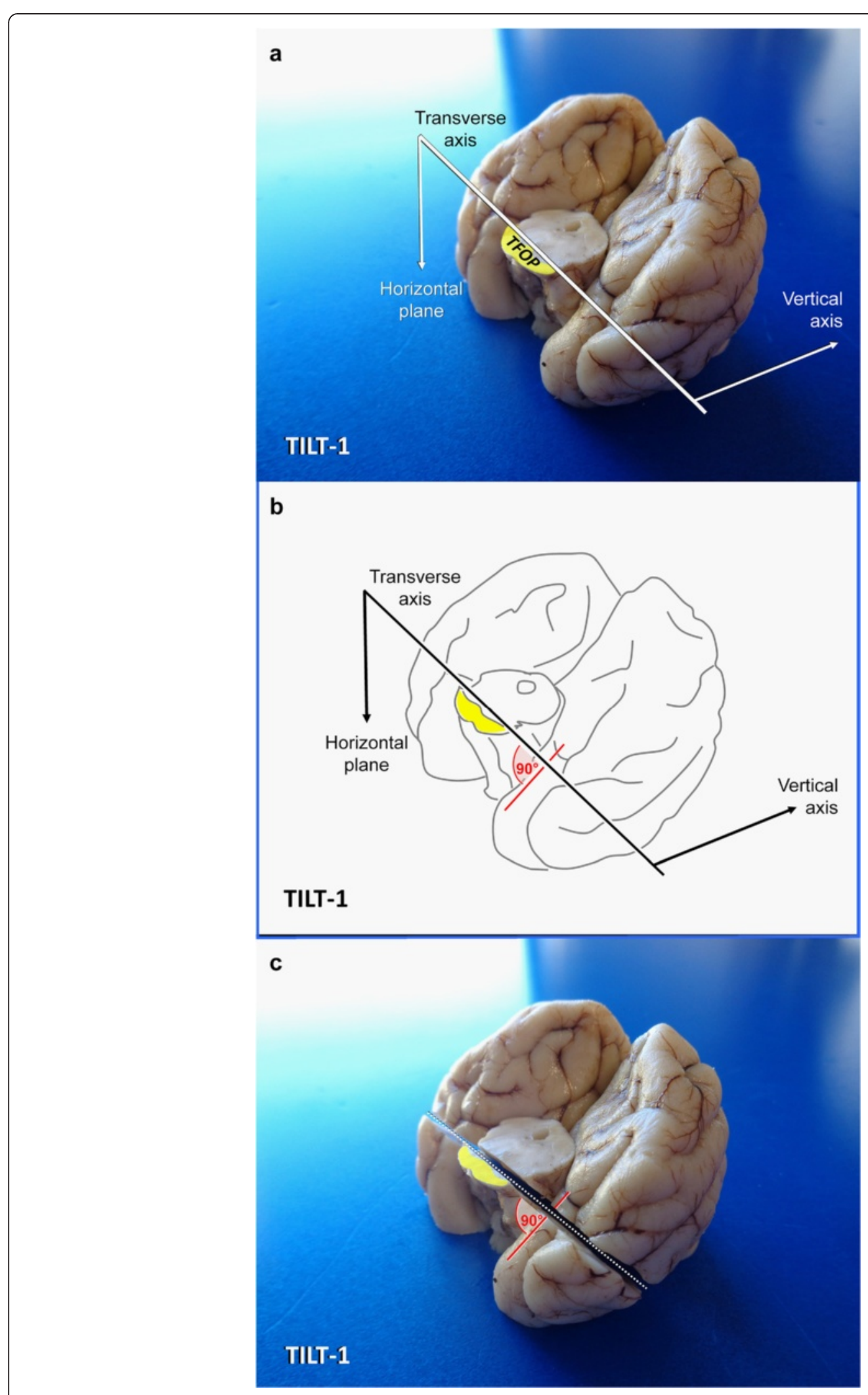

Fig. 7 Dissection of the temporoventral body of the hippocampus via TILT-1 in a dog. MA: mesencephalic aqueduct PAG: periaqueductal grey matter; TFOP: transverse fibres of pons 


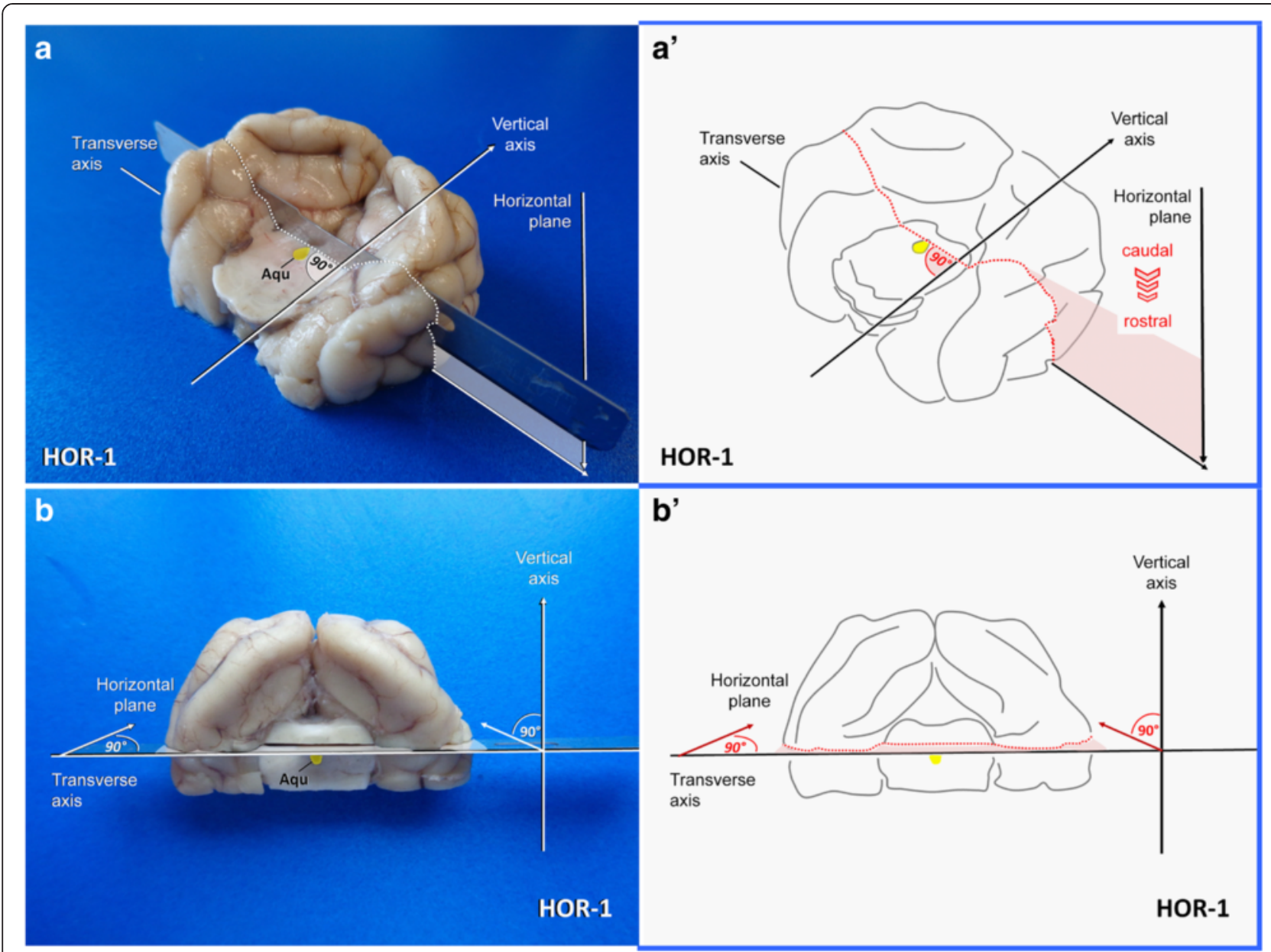

Fig. 8 Dissection of the caudal vertex of hippocampus via HOR-1 in a dog illustrated before $(\mathbf{a}, \mathbf{a}$ ') and after $(\mathbf{b}, \mathbf{b}$ ') procurement of the temporoventral body. Aqu: mesencephalic aqueduct

(UB-1) changes to cerebrum-cerebellum-brain stem ratio, (UB-2) abnormal brain shape and external patterning (lobes, lobules, gyri, folia), (UB-3) increased orifical width of fissures, interfolia spaces and sulci (FISS), (UB-4) leptomeningeal transparency and vascular pattern, (UB-5) changes in the rostrocerebellar space/quadrigeminal area and (UB-6) to the appearance of cranial nerve roots.

Trimmed brain examination (Table 5), on the other hand, checklists (TB-1) course, depth and width of FISS base, (TB-2) volume, ratio, symmetry and delineation of
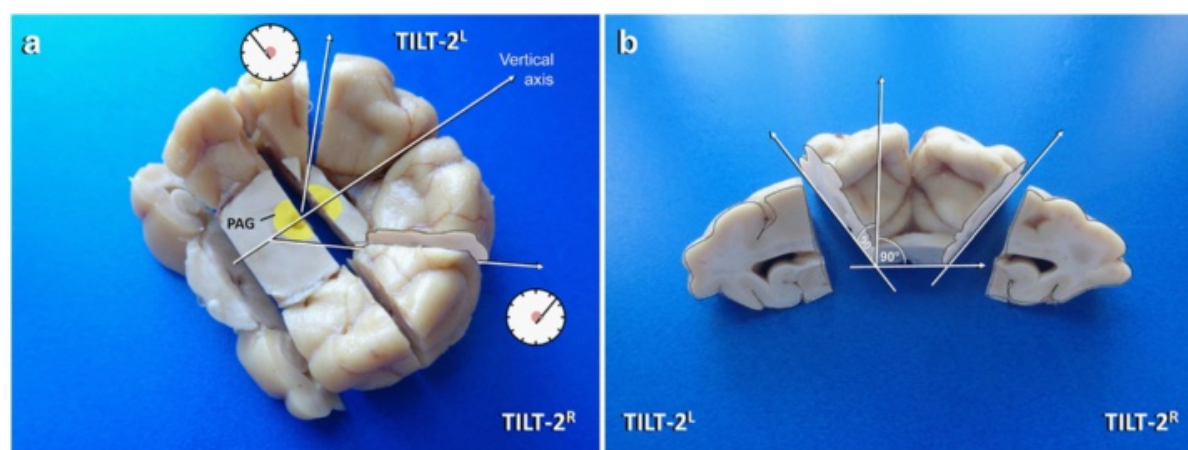

Fig. 9 Dissection (a) and inspection (b, dashed line) of the occipital vertex of the hippocampus in a dog. PAG: periaqueductal gray matter 


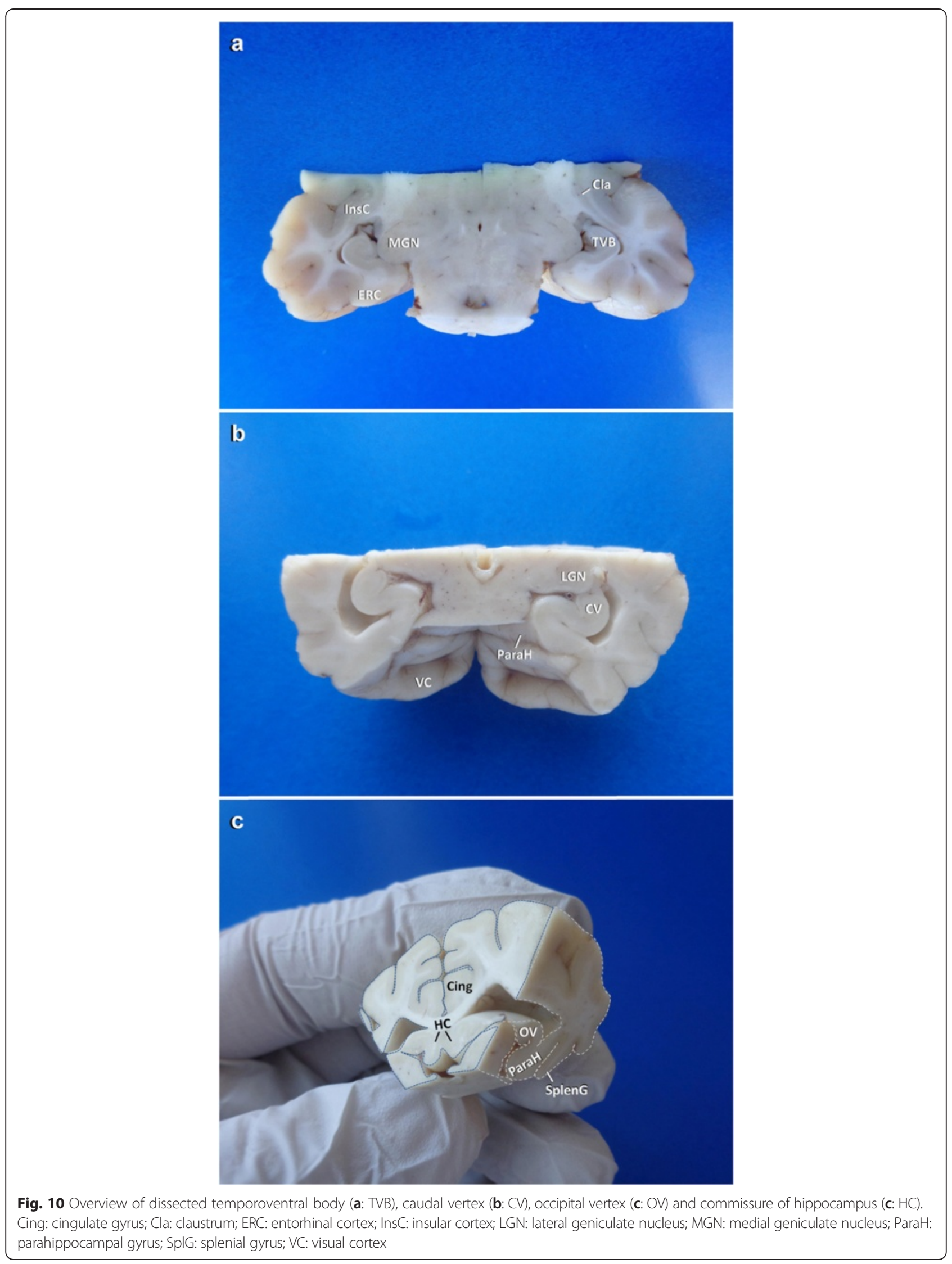


cortical ribbon and subcortical white matter, (TB-3) visibility and symmetry of major white matter tracts and prosencephalic nuclei, (TB-4) preservation of periventricular white matter, (TB-5) appearance of the ventricular surfaces, plexuses and vela, the ventricular size, symmetry and contents.

Pathological lesions throughout the trimming process may become evident simply by (PL-1) discolouration, (PL-2) loss or gain of tissue and (PL-3) changes to the texture (Table 6).

\section{Specific procedures}

Trimming of the occipito-temporal region (tissue block $A$ ) Orientation and planning after transverse section through the pituitary stalk or mammillary bodies

If the brain has been removed in toto, this cut (Fig. 6) should be performed with a long blade to enable fresh sampling of the dorsomedial hippocampus. It also resembles a scout section that allows for rostrocaudal localisation of the dorsomedial and ventrolateral hippocampal boundaries and of the hippocampal (syn. fornical) commissure. The insight gained from this section enables controlled sampling of the hippocampus independent of topographic variations in position and extension of the hippocampus across cats and dogs and different skull types.

In addition to providing a good overview of the middle diencephalon, this section reveals the amygdaloid nucleus that is positioned just rostral to the TVB; this should be included, as it is the second most vulnerable area for seizure-associated sclerosis, in particular in temporal lobe epilepsy identified clinically or on MRI, as well as in epilepsy patients with behavioural abnormalities and in unexplained drug resistance [34-36].

In particular in brachycephalic dogs and in cats, the ventrodorsal axis of the hippocampus is very steep and its concave plane is tilted towards the midline.

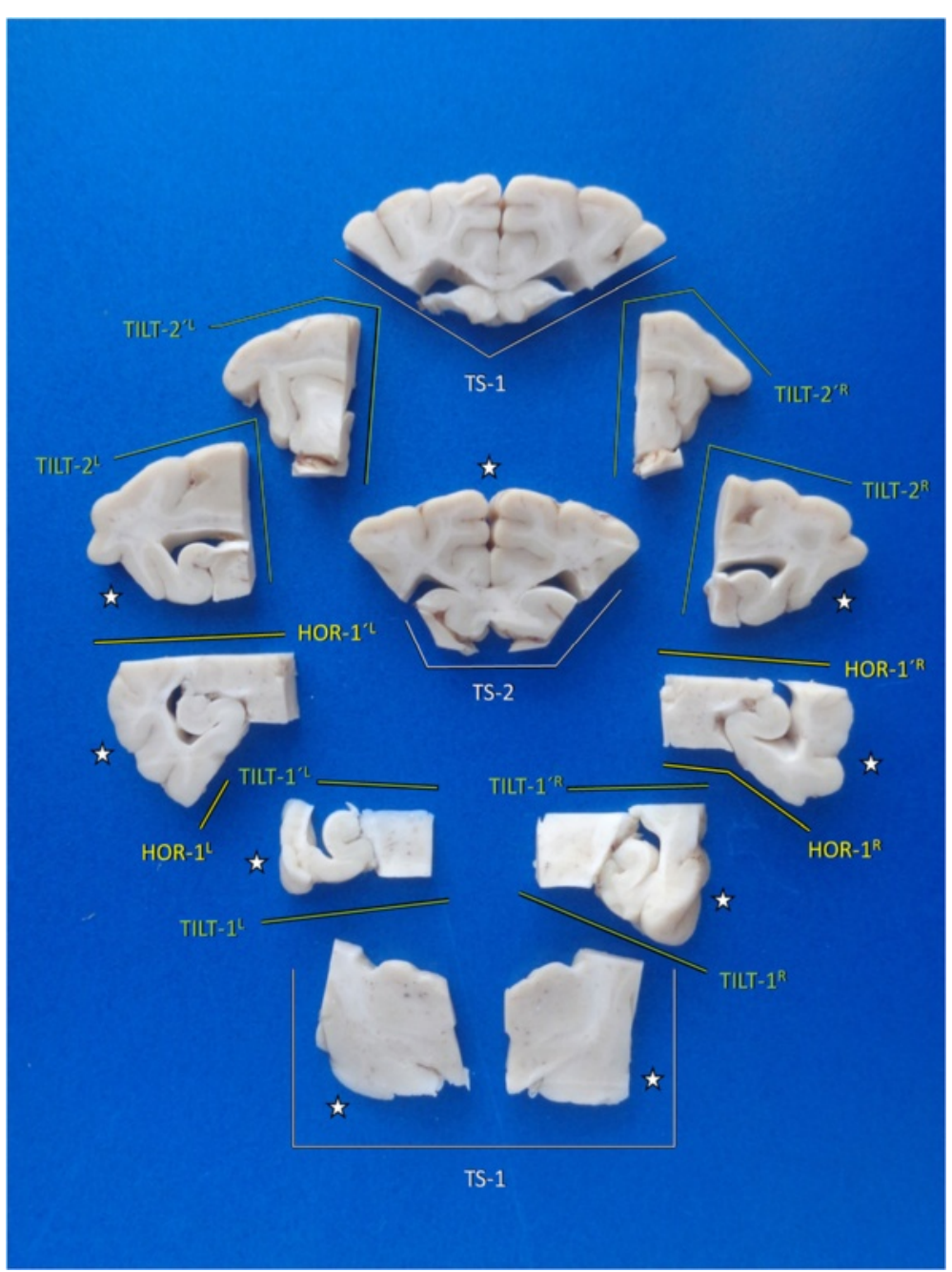

Fig. 11 Overview of main brain slabs of Block A in correct angle of section. A selection of these may be further processed for histology. Asterisks mark our recommendation for systematic epilepsy pathology studies 


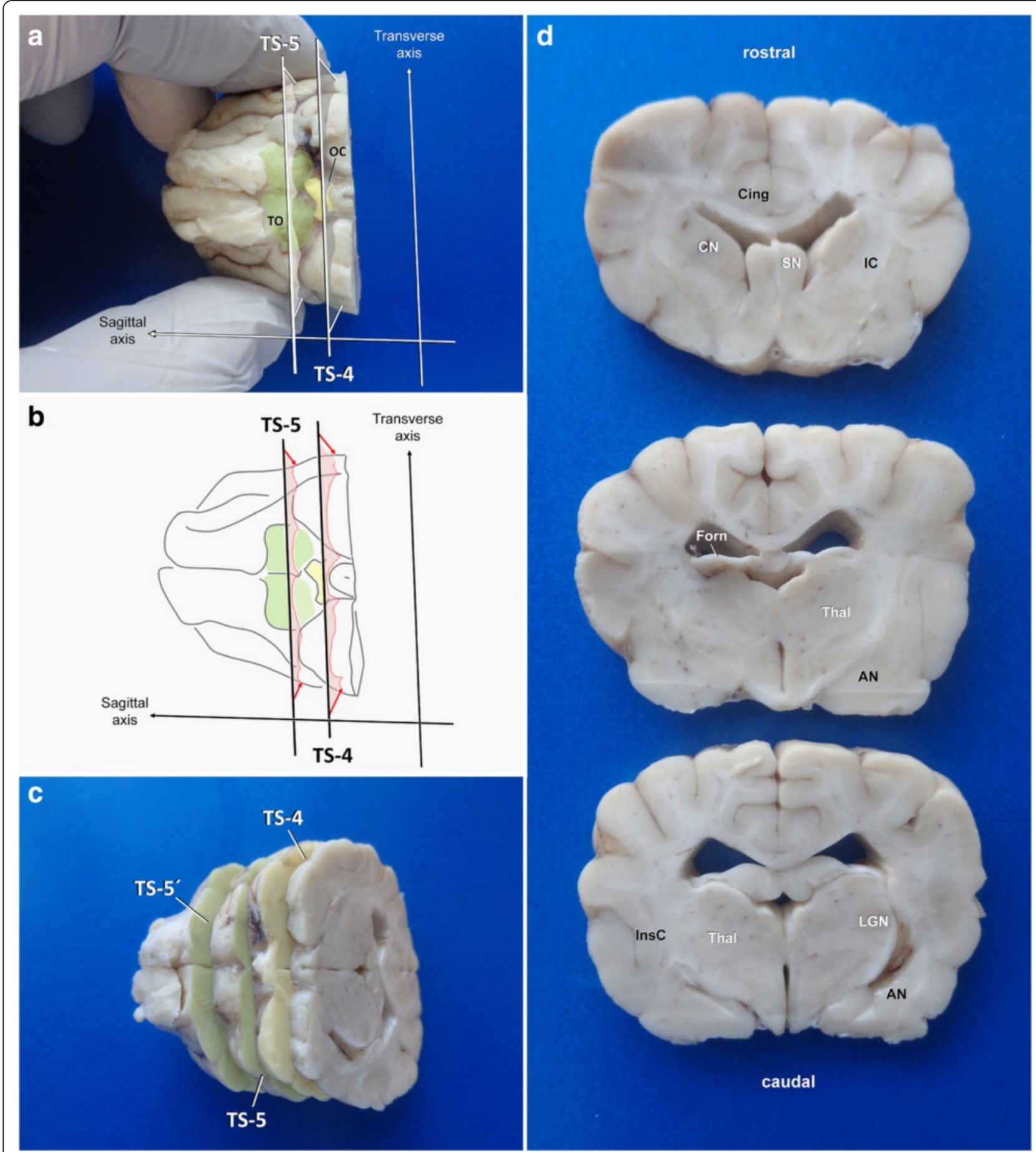

Fig. 12 Planning $(\mathbf{a}, \mathbf{b})$ and performance $(\mathbf{c}, \mathbf{d})$ of dissection of the caudal and middle capsular region. AN: amygdaloid nucleus; Cing: cingulate gyrus; CN: caudate nucleus; Forn: fornix; IC: internal capsule; InsC: insular cortex; LGN: lateral geniculate nucleus; OC: optic chiasm; SN: septal nuclei; Thal: thalamus; TO: tuberculum olfactorium

Meaning that there is no way to obtain perpendicular CA sections by conventional transverse sections of the brain. The sectioning protocol should be tailored with regards to the three-dimensional placement of the hippocampus within the hemispheres (Table 7).
For epilepsy-related research the following segments should be obtained bilaterally from the temporal lobe and hippocampus:

1. amygdaloid nucleus with piriform cortex; 
2. temporoventral body (TVB) with entorhinal cortex;

3. caudal vertex of hippocampal flexure (CV) with post-rhinal cortex;

4. occipital vertex of hippocampal flexure (OV) with parahippocampal gyrus and visual cortex

5. dorsomedial tail at hippocampal commissure (HC) with cingulate gyrus.

Procurement of these regions is manageable for training level I personnel (Table 1) in $10 \mathrm{~min}$ or less if the protocol is strictly followed (Tables $7,8,9$ ).

Procurement of the temporoventral body of the hippocampus For the second section (TS-2; Fig. 3), the caudal part of the brain is approached ventrally. The transverse fibres of the pons (TFOP) are easily recognised in between the convergence of both crura cerebri (rostral) and the origin of the pyramis (caudal). A transverse section of the brain stem is performed with a pointed blade (e.g. scalpel blades no. 11 (cats) or 22 (dogs)), pointed ventrodorsally, just separating the rostral quarter of TFOP from its caudal three quarters (Fig. 5). That way, the caudal surface of the rostral mesencephalic stump ventrally reveals the TFOP, the dorsal border of which serves as the next landmark (Figs. 6 and 7).

Insert a long blade at the horizontal laterolateral axis $\left(0^{\circ}\right.$ angle), where the TFOP border the tegmentum and lower the back edge of the blade ventrally until the sharp edge points towards the caudoventral curvature of the temporal lobes (caudal composite gyrus and base of piriform lobes) at a right angle (Fig. 7).

If you perform the section in this tilted caudoventral to rostrodorsal fashion (TILT-1), you will create a perpendicular section of the entorhinal cortex and TVB; differential evaluation of individual CA segments (e.g. for HS) or evaluation of the dentate gyrus and subiculum pathology will be easy and reliable.

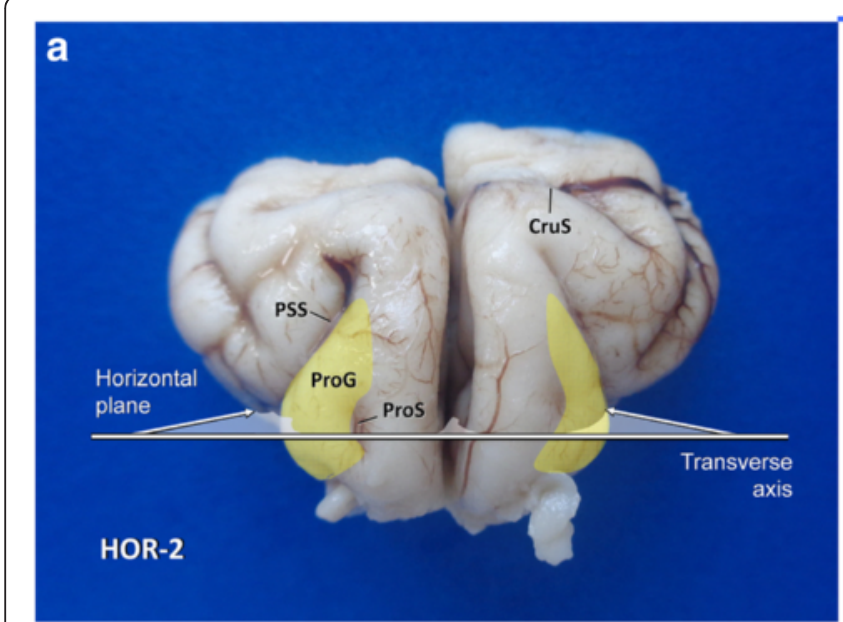

\section{b}
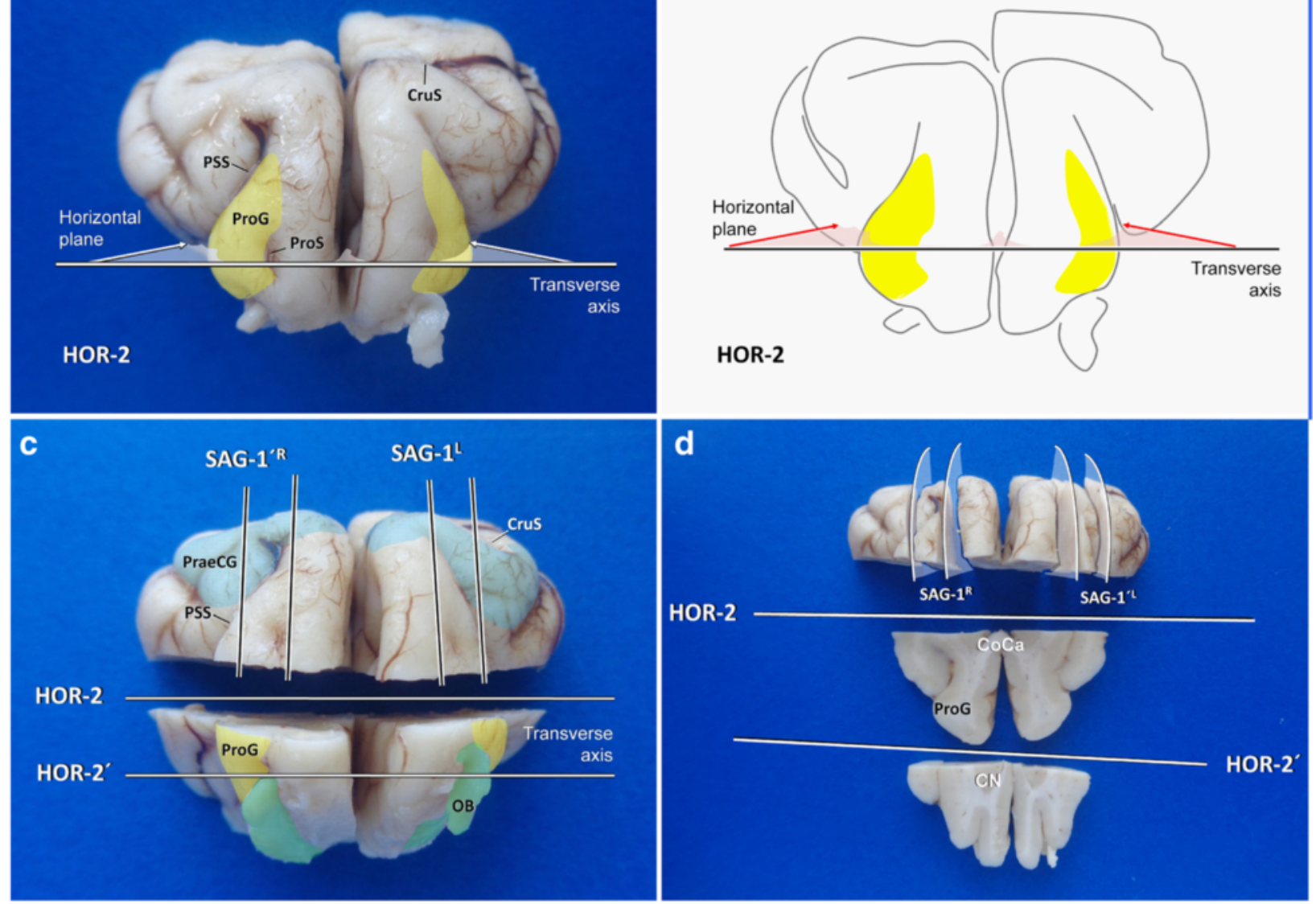

Fig. 13 Planning and performance of fronto-olfactory dissection in a dog; rostral view. CN: caudate nucleus; CoCa: corpus callosum. CruS: cruciate sulcus; OB: olfactory bulb; PraeCG: praecruciate gyrus; ProG: proreus gyrus; Pros: prorean sulcus PSS: presylvian sulcus 


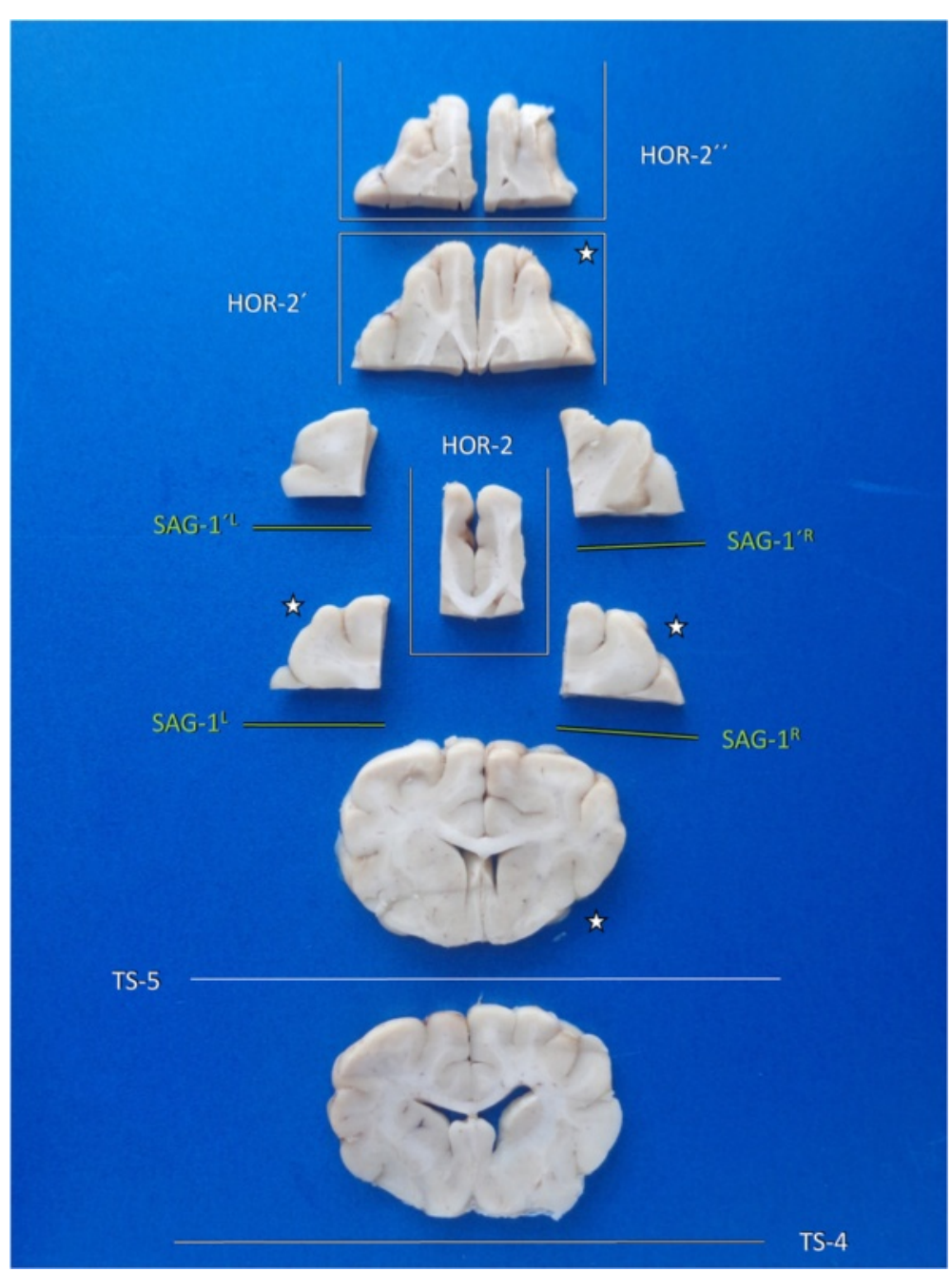

Fig. 14 Overview of main brain slabs of Block B in correct angle of section. A selection of these may be further processed for histology. Asterisks mark our recommendation for systematic epilepsy pathology studies

Adequate slices will be ready to be put in standard cassettes after another section is made parallel to the surface of the wedge (TILT-1') and a longitudinal cut is made through the attached brain stem (see Additional file 1).

\section{Obtainment of the caudal vertex of hippocampal flexure}

At the level of lateral geniculate nuclei (LGN), MR investigation of the hippocampus in angled horizontal plane (or coronal in humans) may allow for assessment of hippocampal atrophy and HS [37]. Even though histopathological changes usually are more advanced in TVB, this adjacent region should be sampled for correlative investigations and for changes to the postrhinal and perirhinal cortices [38-40].

It can be easily approached from caudal aspect again (Fig. 6). A long blade is positioned horizontally at the dorsal border of the mesencephalic aqueduct (Fig. 8). This section (HOR-1) simply is conducted perpendicular to the transectional surface of the mesencephalic stump in a caudorostral fashion (horizontal plane). If the level has been correctly chosen, the LGN are seen just opposite to the hippocampi at the other side of the choroidal fissure (Fig. 10).

\section{Procurement of the occipital vertex of hippocampal flexure}

Additional sections of brain block A allow for a contextual evaluation of the hippocampal OV, the parahippocampal and splenial gyri, both directly exposed to the tentorium and, hence, prone to impingement during herniation [29].

On caudal view of the left occipital lobe, the blade is directed rostrally while the knife points clockwise to 10.30 and the pivot is set slightly left to mesencephalic aequeduct, where the periaquaeductal grey matter dorsolaterally is expected to border the tegmentum (TILT-2 ${ }^{\text {L }}$ Fig. 6; Fig. 9). 


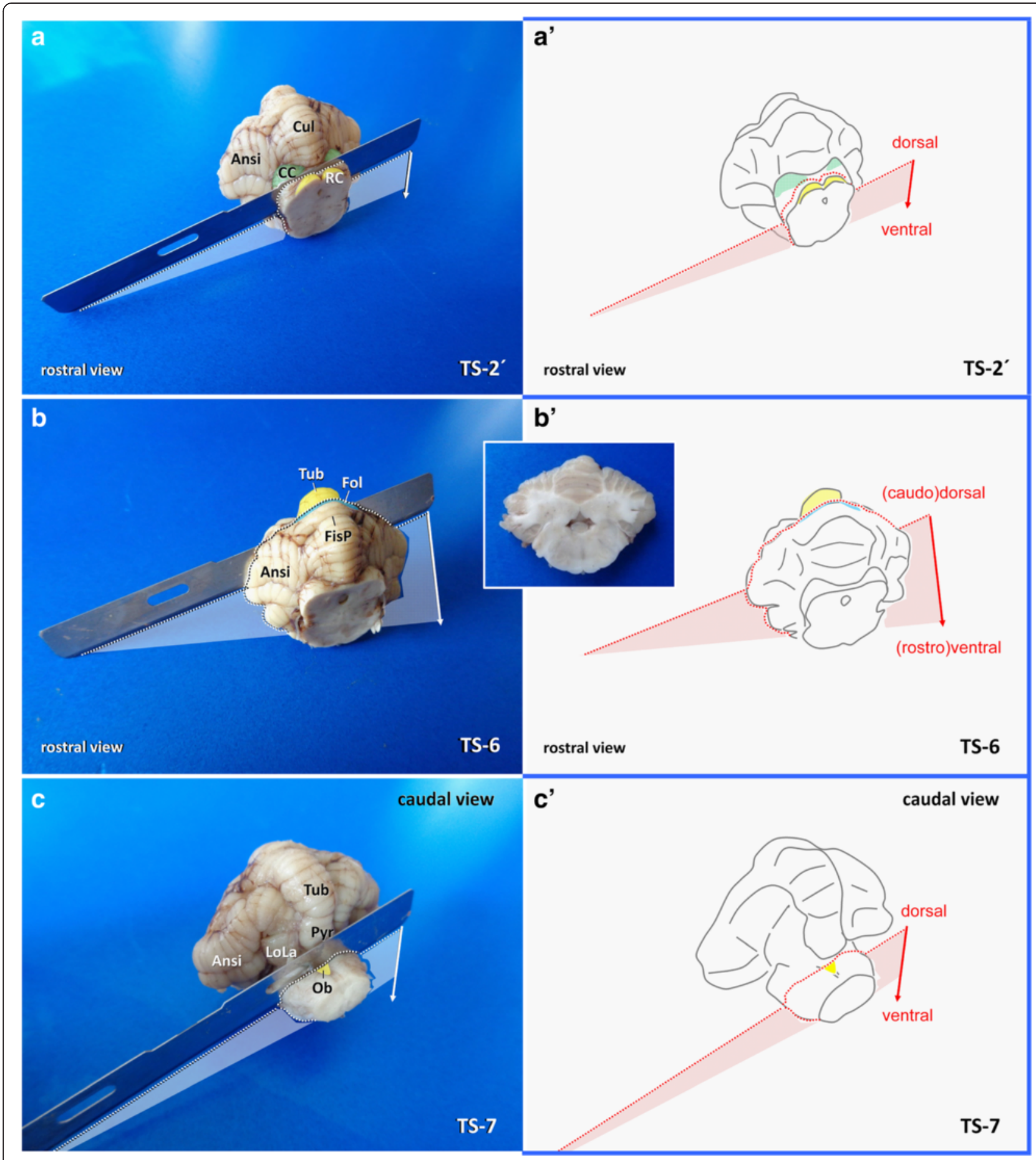

Fig. 15 Dissection of central midbrain ( $\left.\mathbf{a}, \mathbf{a}^{\prime}\right)$, central metencephalon ( $\left.\mathbf{b}, \mathbf{b}^{\prime}\right)$ and obex area $\left(\mathbf{c}, \mathbf{c}^{\prime}\right)$ in three steps. Ansi: ansiforme lobule; CC: caudal colliculus; Cul: culmen; FisP: fissura prima; Fol; folium; LoLa: lateral lobules; Ob: obex; Pyr: pyramis; RC: rostral colliculus.; Tub: tuber. Canine brain

That way, the blade is supposed to cut the parahippocampal gyrus and hippocampus perpendicularly. For the right hemisphere the procedure is repeated just mirror inverted (TILT-2R; Figs. 6 and 9).

\section{Procurement of the dorsomedial hippocampal tail and} hippocampal commissure

Longitudinal variations of pathological lesions along the septotemporal axis are frequently seen but have been 
rarely associated to distinct aetiologies. Exceptions are toxicopathological studies and rodent models of epilepsy [11]. Respecting the varying connectivities, functions and metabolism, and in particular our lack of knowledge regarding selective vulnerabilities and involvement, the dorsomedial hippocampus should not be omitted.

After obtainment of the occipital vertices, a wedge shaped piece of block A remains containing the occipitomesial cortex, marginal and ectomarginal gyri bilaterally. Rostral inspection of this wedge allows for judgement of the rostral tip of the hippocampal tail in the midline, ventrally attached to the fornix. A transverse section (TS-3) should be performed just about $1 \mathrm{~mm}$ caudal to this point. This level usually provides a perpendicular view of the dorsal CA segments and DG and of the hippocampal commissure (Figs. 4 and 10) that may be one of the pathways wiring excitations to the contralateral side of the brain.

A survey on the brain slides possibly sampled by trimming of tissue block A is provided in Fig. 11.
Trimming of the parieto-frontal region (tissue block B)

Essential parts of parietal cortex will have already been collected at the thalamic level. For gross inspection, further transverse sections should be performed from ventral at or just proximal of the optic chiasm (TS-4; Figs. 3 and 12) to investigate septal nuclei, fornical body, rostral commissure and basal nuclei. Depending on the size of the brain, a parallel transverse section through the middle part of the olfactory tuberculum (TS-5) provides a representative view of the frontal lobe, including the caudal parts of frontal cortex, striatum and the capsules (Figs. 3 and 12).

Further trimming of the remaining tissue block $\mathrm{B}$ (Table 8) mainly is dedicated to explore motor areas of frontal cortex and the olfactory lobe, which resembles another low threshold area for seizure generation and lesions of which are rarely associated with neurological signs in dogs and cats other than seizures.

It proves useful to approach the olfactory bulb and cortex, its connections to the periventricular brain and
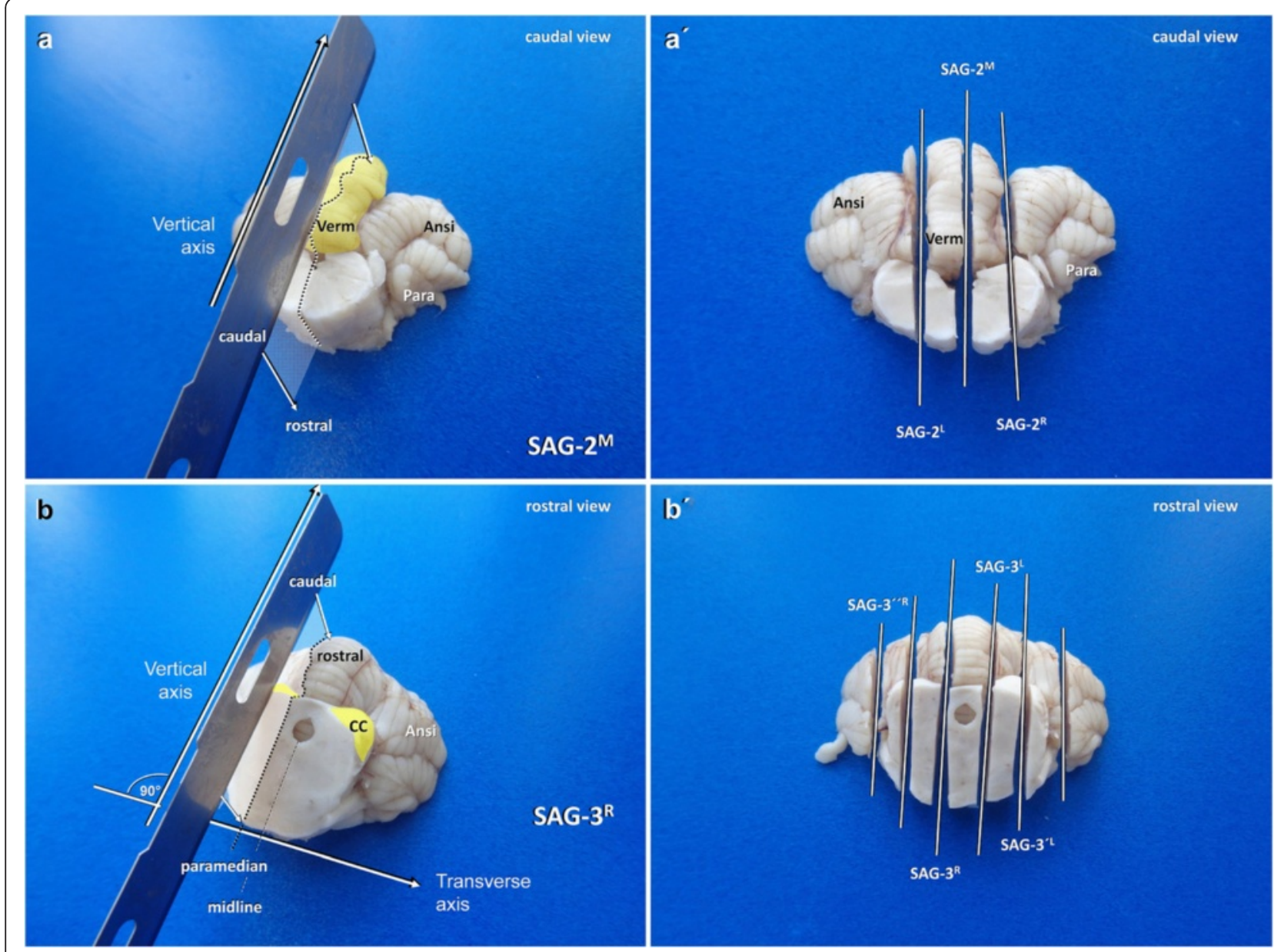

Fig. 16 Sagittal dissection of the caudal (a, a') and rostral (b, b') cerebellar lobes and the associated brain stem in a dog. Ansi: ansiform lobule; CC: caudal colliculus; Para: paraflocculus; Verm: vermis 


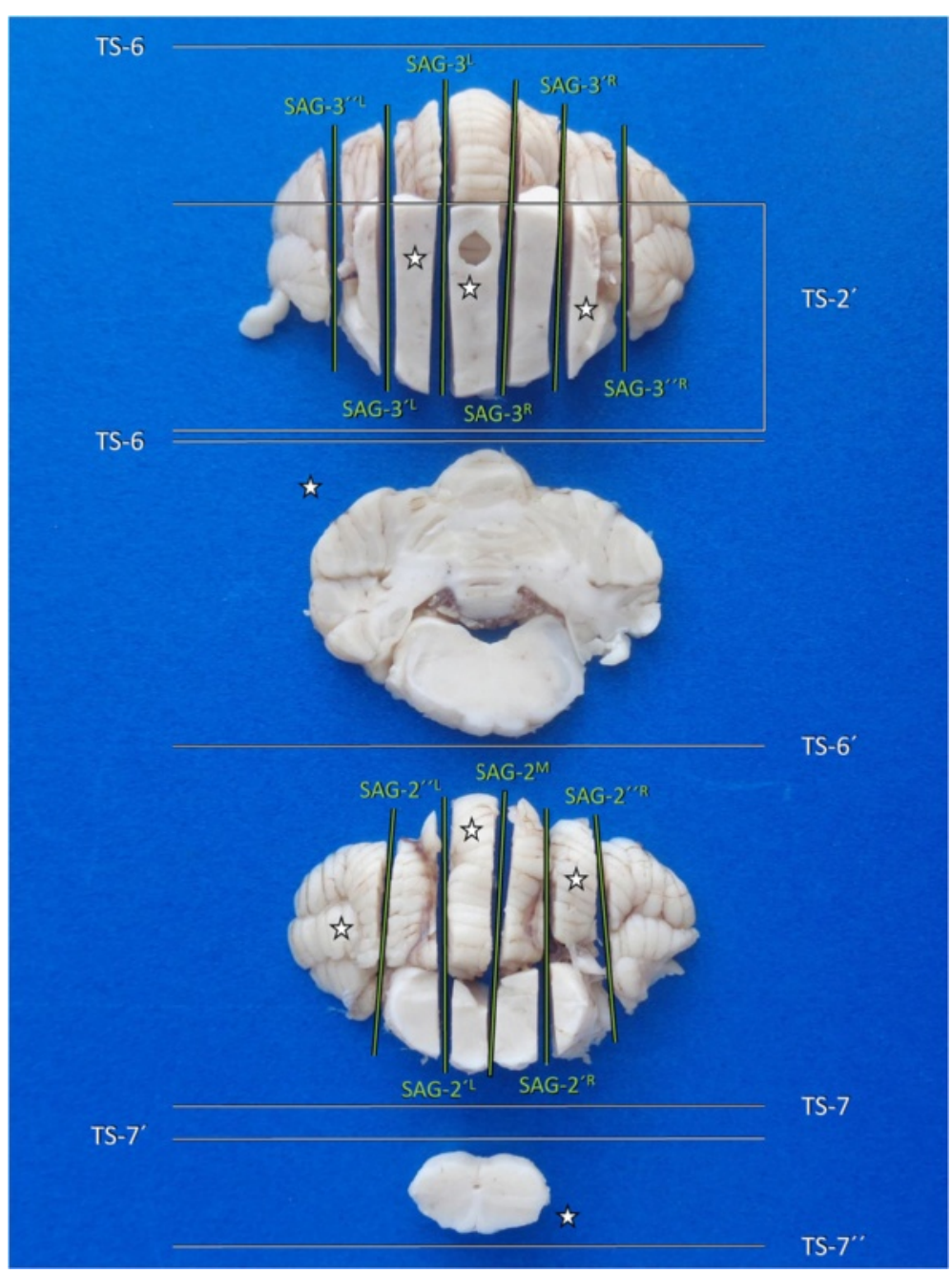

Fig. 17 Overview of main brain slabs of Block $C$ in correct angle of section. A selection of these may be further processed for histology. Asterisks mark our recommendation for systematic epilepsy pathology studies

subventricular zones using horizontal sections. To conduct the first horizontal section (HOR-2), the blade is inserted in laterolateral axis at the proreus gyrus and the tissue is cut in rostrocaudal direction (Fig. 13). With the previous transverse cut, set caudal to the genu of the corpus callosum, both hemispheric parts stay connected, which facilitates cutting and processing. Depending on the brain size, one or two further horizontal sections (HOR-2', -2") are performed at 3-4 $\mathrm{mm}$ interslice distances ventral to HOR-2 (Fig. 13).

Having achieved this, two sagittal sections through the lateral third of the proreus gyrus (SAG-1Left/Right) and again about $3 \mathrm{~mm}$ lateral to these (SAG-1'L/R) allow for inspection of and sampling of motor cortex, flanking the cruciate sulcus rostrally (pre-cruciate) and caudally (postcruciate) (Fig. 13). Further sagittal sections in vertical plane (SAG-1" L/R) may be taken if for diagnostic purposes.
An example of the tissue slabs achieved by trimming of tissue block B is provided in Fig. 14.

\section{Trimming of the hindbrain (tissue block $\mathrm{C}$ )}

Brainstem and cerebellar seizures have not been reported in domestic animals yet but there is some histological evidence that epilepsy in dogs maybe associated with cerebellocortical abnormalities [8]. Likewise, cerebellar atrophy is observed in about $25 \%$ of human epileptics presented at autopsy [41] with some variabilities between anterior versus posterior lobe involvement [42]. Cerebellar changes either are related to the seizure-syndrome [8], to antiepileptic drug toxicity [42] or to specific epileptogenic aetiologies, such as hypoxia, ischaemia, intoxication or mitochondrial disease [42, 43]. In contrast, there is no systematic interdependence between epilepsy and brainstem lesions. 
Table 9 Trimming and sampling of midbrain and hindbrain (Block C)

\begin{tabular}{|c|c|c|c|c|c|c|}
\hline Cut & Time & View/specimen & Landmarks and cutting levels & $\begin{array}{l}\text { Orientation of } \\
\text { section }\end{array}$ & Aim/harvest & Difficulty \\
\hline \multirow[t]{3}{*}{ TS-2' } & \multirow[t]{3}{*}{$21 \mathrm{~min}$} & \multirow[t]{3}{*}{$\begin{array}{l}\text { Lateral view of } \\
\text { the midbrain }\end{array}$} & \multirow{3}{*}{$\begin{array}{l}\text { Transverse line through the } \\
\text { intercollicular area (small brains) } \\
\text { or caudal colliculi (large brains) }\end{array}$} & $\begin{array}{l}2 D \text { knife axis: } \\
\text { ventrodorsal. }\end{array}$ & \multirow[t]{3}{*}{ Standard section of the midbrain } & \multirow[t]{3}{*}{ Easy } \\
\hline & & & & Plane: transverse. & & \\
\hline & & & & $\begin{array}{l}\text { Blade movement: } \\
\text { laterolateral. }\end{array}$ & & \\
\hline \multirow[t]{3}{*}{ TS-6 } & \multirow[t]{3}{*}{$22 \mathrm{~min}$} & \multirow[t]{3}{*}{$\begin{array}{l}\text { Dorsal view of } \\
\text { the cerebellum }\end{array}$} & $\begin{array}{l}\text { 6: Transverse line just caudal to } \\
\text { the primary fissure. }\end{array}$ & $\begin{array}{l}\text { 2D knife axis: } \\
\text { laterolateral. }\end{array}$ & $\begin{array}{l}\text { Standard cross section of cerebellum } \\
\text { and medulla oblongata. }\end{array}$ & \multirow[t]{3}{*}{ Easy } \\
\hline & & & \multirow{2}{*}{$\begin{array}{l}6 \text { '...followed by a parallel section } \\
\text { with } 3 \mathrm{~mm} \text { slice thickness }\end{array}$} & Plane: transverse. & \multirow{2}{*}{$\begin{array}{l}\text { Shows central vermis, hemispheres, } \\
\text { paraflocculus, flocculonodular lobe, } \\
\text { cerebellar roof, caudal/middle } \\
\text { peduncles and medulla oblongata. }\end{array}$} & \\
\hline & & & & $\begin{array}{l}\text { Blade movement: } \\
\text { dorsoventral along } \\
\text { the midline axis of } \\
\text { cerebellar } \\
\text { hemispheres. }\end{array}$ & & \\
\hline \multirow[t]{3}{*}{ TS-7 } & \multirow[t]{3}{*}{$24 \mathrm{~min}$} & \multirow{3}{*}{$\begin{array}{l}\text { Caudodorsal view } \\
\text { of the medullary } \\
\text { stump }\end{array}$} & \multirow[t]{3}{*}{$\begin{array}{l}\text { Transverse line close to the } \\
\text { obex }\end{array}$} & $\begin{array}{l}\text { 2D knife axis: } \\
\text { laterolateral. }\end{array}$ & $\begin{array}{l}\text { Standard section of the lower } \\
\text { brainstem. }\end{array}$ & \multirow[t]{3}{*}{ Easy } \\
\hline & & & & Plane: transverse. & Shows spinal tracts, vagal and & \\
\hline & & & & $\begin{array}{l}\text { Blade movement: } \\
\text { dorsoventral. }\end{array}$ & $\begin{array}{l}\text { associated nuclei, proprioceptive } \\
\text { nuclei. }\end{array}$ & \\
\hline \multirow[t]{3}{*}{ SAG-2M } & \multirow[t]{3}{*}{$25 \min$} & \multirow{3}{*}{$\begin{array}{l}\text { Caudal view of } \\
\text { cerebellum and } \\
\text { medulla }\end{array}$} & \multirow{3}{*}{$\begin{array}{l}\text { Sagittal midline section through } \\
\text { caudal cerebellar vermis and } \\
\text { underlying medulla. }\end{array}$} & $\begin{array}{l}2 D \text { knife axis: } \\
\text { ventrodorsal. }\end{array}$ & $\begin{array}{l}\text { Standard section of cerebellar caudal } \\
\text { lobe and in particular useful in }\end{array}$ & \multirow[t]{3}{*}{ Easy } \\
\hline & & & & $\begin{array}{l}\text { Plane: sagittal, } \\
\text { midline. }\end{array}$ & $\begin{array}{l}\text { suspected foramen magnum } \\
\text { herniation. }\end{array}$ & \\
\hline & & & & $\begin{array}{l}\text { Blade movement: } \\
\text { caudorostral. }\end{array}$ & $\begin{array}{l}\text { Shows caudal vermis and midline } \\
\text { medulla. }\end{array}$ & \\
\hline \multirow[t]{3}{*}{$\begin{array}{l}S A G-2^{\prime} L / R \& \\
S A G-2 " L / R\end{array}$} & \multirow[t]{3}{*}{$27 \mathrm{~min}$} & \multirow[t]{3}{*}{$\begin{array}{l}\text { Caudal view of } \\
\text { cerebellum and } \\
\text { medulla }\end{array}$} & $\begin{array}{l}\text { 2'L/R: Sagittal lines, lateral und } \\
\text { parallel to SAG-2M on each } \\
\text { side. }\end{array}$ & $\begin{array}{l}2 D \text { knife axis: } \\
\text { ventrodorsal. }\end{array}$ & $\begin{array}{l}\text { Standard sections for evaluation of } \\
\text { caudal cerebellar hemispheres. }\end{array}$ & \multirow[t]{3}{*}{ Easy } \\
\hline & & & \multirow[t]{2}{*}{$\begin{array}{l}\text { 2"L/R: .followed by parallel } \\
\text { sections } 3 \mathrm{~mm} \text { lateral to } 2{ }^{\prime} \mathrm{L} / \mathrm{R} \text {. }\end{array}$} & $\begin{array}{l}\text { Plane: sagittal, } \\
\text { paramedian. }\end{array}$ & \multirow{2}{*}{$\begin{array}{l}\text { Shows in particular lobules ansiformis } \\
\text { and dorsolateral proprioceptive and } \\
\text { vestibular areas of medulla. }\end{array}$} & \\
\hline & & & & $\begin{array}{l}\text { Blade movement: } \\
\text { rostrocaudal. }\end{array}$ & & \\
\hline \multirow[t]{3}{*}{$\begin{array}{l}S A G-3^{\prime} L / R \text { \& } \\
S A G-3 " L / R\end{array}$} & \multirow[t]{3}{*}{$29 \min$} & \multirow{3}{*}{$\begin{array}{l}\text { Rostral view of the } \\
\text { caudal midbrain } \\
\text { stump and the } \\
\text { rostral cerebellar } \\
\text { lobe }\end{array}$} & \multirow{2}{*}{$\begin{array}{l}\text { 3'L/R: Sagittal lines through the } \\
\text { lateral boundaries of } \\
\text { periaqueductal grey matter, } \\
\text { about } 1-2 \mathrm{~mm} \text { lateral to the } \\
\text { aqueduct. }\end{array}$} & $\begin{array}{l}2 D \text { knife axis: } \\
\text { ventrodorsal }\end{array}$ & \multirow{3}{*}{$\begin{array}{l}\text { Standard sections for evaluation of } \\
\text { rostral cerebellar lobe and in particular } \\
\text { the effects of transtentorial herniation, } \\
\text { as well as of pontomesencephalic } \\
\text { transition, including caudal colliculi, } \\
\text { leminiscus and lateral tegmental nuclei }\end{array}$} & \multirow[t]{3}{*}{ Easy } \\
\hline & & & & $\begin{array}{l}\text { Plane: sagittal, } \\
\text { paramedian. }\end{array}$ & & \\
\hline & & & $\begin{array}{l}\text { 3"L/R: .followed by parallel } \\
\text { sections } 3 \mathrm{~mm} \text { lateral to } 3^{\prime} \mathrm{L} / \mathrm{R} \text {. }\end{array}$ & $\begin{array}{l}\text { Blade movement: } \\
\text { rostrocaudal. }\end{array}$ & & \\
\hline
\end{tabular}

Sampling of these areas pretty much underlies laboratory specific protocols with the basic requirement to obtain sections from the cerebellum in two planes and to investigate vital brainstem centres (Table 9).

In the following, one possible approach is illustrated which, based upon the experience gained at our own laboratories (LMU Munich, UAB Barcelona), has proven easy to perform and to standardise and is effective in picking-up lesions blindly.

\section{Procurement of mesencephalon}

After TS-2, a transversely oriented tissue section is taken from the caudal mesencephalic stump, either at the intercollicular level or the level of the rostral colliculi (TS-2'). The caudal colliculi are sampled later on via paramedian sagittal sections in vertical plane (see below).

\section{Procurement of cerebellum and medulla oblongata at mid-cerebellar level}

In order to obtain a representative transverse section, the cerebellum is approached from dorsal. After mesencephalic sampling, sectioning (TS-6; Fig. 15) is carried out in a dorsoventral direction along the dorsoventral axis of the cerebellar hemispheres, with the long blade being inserted 2-3 $\mathrm{mm}$ caudal to the primary fissure. The parallel section (TS-6'), necessary to obtain a tissue slice is then performed 
Table 10 Example of a CNS specific processing/embedding cycle [45]

\begin{tabular}{lll}
\hline Incubation time & Chemical & Temperature \\
\hline $6 \mathrm{~h}$ & $70 \%$ ethanol & $40{ }^{\circ} \mathrm{C}$ \\
$4 \mathrm{~h}$ & $80 \%$ ethanol & $40{ }^{\circ} \mathrm{C}$ \\
$4 \mathrm{~h}$ & $90 \%$ ethanol & $40{ }^{\circ} \mathrm{C}$ \\
$4 \mathrm{~h}$ & $100 \%$ ethanol & $40{ }^{\circ} \mathrm{C}$ \\
$4 \mathrm{~h}$ & $100 \%$ ethanol & $40{ }^{\circ} \mathrm{C}$ \\
$4 \mathrm{~h}$ & $100 \%$ ethanol & $40{ }^{\circ} \mathrm{C}$ \\
$2 \mathrm{~h}$ & xylene & $40{ }^{\circ} \mathrm{C}$ \\
$2 \mathrm{~h}$ & xylene & $40{ }^{\circ} \mathrm{C}$ \\
$2 \mathrm{~h}$ & xylene & $40{ }^{\circ} \mathrm{C}$ \\
$1 \mathrm{~h}$ & paraffin & $60{ }^{\circ} \mathrm{C}$ \\
$1 \mathrm{~h}$ & paraffin & $60{ }^{a} \mathrm{C}$ \\
$1 \mathrm{~h}$ & paraffin $^{\mathrm{a}}$ & $60{ }^{\circ} \mathrm{C}$ \\
$3 \mathrm{~h}$ & paraffin $^{a}$ & $60{ }^{\circ} \mathrm{C}$ \\
\hline
\end{tabular}

Cycle times differ if fixation is performed with higher concentrations of formalin as occasionally recommended for large specimens

${ }^{a}$ We recommend use of paraffin with $4 \%$ DMSO (Paraplast ${ }^{\ominus}$, Leica Biosystems, Nussloch)

either on the rostral or caudal stump, depending on the placement of the cerebellar roof nuclei (Additional file 1).

This section provides a detailed view on the flocculonodular lobe, paraflocculus, paravermis and dorsal vermis, the cerebellar roof, including the associated nuclei, the caudal peduncles or lateral foramina, and the medulla at its largest laterolateral diameter that contains in particular the dorsolateral sensory nuclei and motor nuclei of CN-VI and CN-VII (Fig. 15).

\section{Procurement of the caudal vermis and the autonomic centres of the caudal brainstem}

Even though the last section being broadly considered representative of the cerebellum, it does not contain the essential spinocerebellar parts of the vermis, since the nodulus belongs to the vestibulocerebellum and the dorsal aspects of the vermis receive cortico-pontocerebellar inputs. Furthermore, the medulla being cut at mid rostocaudal level does not contain the respiratory control centre. In particular in combined (medullocerebellar) midline pathologies, such as in transforaminal cerebellar herniation [29], it is essential to study the micromorphology of these areas in detail.

Most of the vagal nerve nuclei and related parasympathetic nuclei are preserved by gathering a transversely oriented slab of brainstem from the obex area (TS-7; Fig. 15).

After that, the caudal part of the cerebellum and brain stem can be sectioned sagittally through the midline (SAG-2 M) and in sequential paramedian slides (SAG2'L/R; Fig. 16).

Histological slides from these brain slices allow for inspection of the comb-like two dimensional organisation of the Purkinje cell dendrites, which is not possible on transverse sections. It further elucidates histopathological sequelae of transtentorial herniation, which may be subtle and restricted to the lingula or pyramis.

\section{Obtainment of rostral cerebellar lobe and caudal mesencephalon}

Concerning, the transtentorial border zone, the implied brain shifting and associated problems, the cerebellum may have suffered from descending occipital lobes. In contrast to transforaminal herniation, caudal transtentorial protrusion of the occipital lobes results in a lesion of the paravermal areas of the rostral cerebellum [29]. Midline sections, hence, do not necessarily reflect the effects of impingement. Evaluation of the rostral lobe further may pick-up the anterior type of epilepsy-related cerebellar atrophy [42].

Investigation of the brainstem underlying the rostral cerebellar lobe, on the other hand, could help to detect systemic ictogenic conditions such as global ischaemia [44]

There are two different assessment modes that may be applied, depending on the individual case scenario. The easier procedure (Table 9, Fig. 16) employs two parallel sagittal or slightly inwardly rotated paramedial sections in the rostrocaudal direction through caudal colliculi and/or rostral peduncles (CC/RP) and the caudally adjacent paravermis $(\mathbf{S A G}-\mathbf{3} \mathbf{L} / \mathbf{R})$ as well as

Table 11 Essential data (Level I) that are required to be collected for a meaningful post-mortem examination

\begin{tabular}{ll}
\hline l. Data on the animal and & \# breed, age, gender \\
pedigree & \# evidence of seizures or other paroxysmal \\
& and neurological diseases in the pedigree \\
& \# usual food and treats, dietary changes \\
& \# exposure to toxins/medications \\
& \# possible triggers \\
II. Data on the events \& & \# seizure onset semiology and \\
& characteristics \\
& \# evidence of automatisms \\
& \# interictal neurological signs/ \\
& neurolocalisation \\
& \# seizure frequency and duration \\
& \# abnormal MRI and EEG findings \\
& \# abnormalities on blood work, CSF and \\
& urine analysis \\
& \# treatment scheme and response \\
& \# changes to semiology \\
& \# recently acquired medical problems \\
& \# time span from last seizure to death \\
& \# natural death or euthanasia \\
& \# death in status epilepticus \\
III. Epicrisis &
\end{tabular}


parallel sections (SAG-3'L/R) conducted $3 \mathrm{~mm}$ farther lateral (Fig. 16).

Figure 17 provides a summary of the possible tissue slabs generated through the described protocol for tissue block C trimming (Table 9).

An alternative option, used in distinct rostral compression of the cerebellum would be a horizontal section of the cerebellum just dorsal to the colliculi with subsequent bilateral sagittal sections through the "decapitated" CC/RP.

\section{Post-Trimming procedures and histological staining}

Independent of the sections necessary for the requested diagnosis, processing of the brain sections to paraffin blocks is advisable to prevent the brain tissue from formalin-induced, excessive aldehyde bridging and DNA fragmentation. Processing cycles vary slightly in between different labs and run on standard or, even better, dedicated CNS programs with or without dimethylsulfoxide permeabilisation [45]. Table 10 provides an example of a CNS adapted paraffin embedding cycle. It has to be made clear that any attempt to accelerate histoprocessing will impact negatively on the tissue quality and thereby compromise detection of degenerative cytopathological features. Identification of infiltrative changes will be less severe.

Staining protocols, in addition to haematoxylin-eosin (H.E.), are to be chosen in accordance to (1) the requirements of the individual case, (2) the investigational purpose and (3) financial constraints. Overviews on neuropathological standard stains are provided elsewhere [46]

For elucidation of epilepsy-related changes it proved beneficial to highlight the regional drop-out of nerve cells by cresyl violet-based stains such as Nissl stain (without myelin staining) or Kluver Barrera stain (with myelin staining). In very fresh samples taken via brain surgery or early post-mortem, NeuN immunohistochemistry may be superior for highlighting neurons [47] but this procedure also is far more expensive and immunoreactivity rapidly decreases post-mortem and with prolonged fixation periods.

Apart from providing an insight into nerve cell density neuronal stainings also facilitate the detection of histoarchitectural grey matter changes, such as dyslamination, and heterotopia [47]. Dysmorphic neurons, on the other hand, become most obvious on staining for microtubule associated protein 2 (MAP-2) and neurofilament staining. Just the interpretation requires some experience in neuronal cytoarchitecture [47].

In post-mortem samples, differentiation of post- and intra-ictal neuronal necrosis from terminal ischaemic changes can be problematic, in particular if prefinal seizure episodes might have gone unseen. In such cases, clarification of the fate of eosinophilic neurons can be achieved using FluoroJade- $\mathrm{B}^{\bullet}$ or $-\mathrm{C}^{\bullet}[48,49]$. Other, more specific markers of degeneration, necrosis and apoptosis may be used based on the aim of investigation and the experiences of the investigator.

Experience also comes into effect with evaluation of glial response. Reactive astroglial changes occur with or without preceding neuronal degeneration. Protoplasmatic astrogliosis may be missed if the examiner is not familiar with astroglial cytomorphological details. It becomes even more sophisticated to identify fibrillary astrogliosis and isomorphic astrocytosis, without cytoplasmic accumulation. Intraobserver's sensitivity can be increased for both fibrillary and protoplasmic astrogliosis by staining for the filament glial fibrillary acidic protein (GFAP) and by use of the overall available marker vimentin [17].

Most recently, the role of autoimmune mechanisms [14] and neuroinflammation have gained new attention in veterinary epileptology and led to introduction of immunosuppressive and anti-inflammatory treatment concepts [50]. With regards to autoimmune encephalitis, conventional markers for lymphocyte subsets, antibodies and complement factors may shed light on their specific involvement [14], while cellular infiltrates are seen on standard stains (e.g. H.E.).

With ionized calcium-binding molecule (Iba1), even subtle changes to the microglial activity can be nicely visualised in paraffin embedded tissues of different animal species [51] including the hippocampi of dogs [52]. In combination with CD-163, It has also proved to be a reliable marker for distinction of local microglial response and invasive macrophages in canine encephalitis [53].

Breakdown of the blood brain barrier due to seizures or their primary pathologies will lead to pervasive effects due to extravasation of fluid and possibly epilepsy promoting molecules [54]. Postictal brain oedema usually is quite prominent and its extension into the white matter remains visible for a prolonged period with proper brain processing (see above). In grey matter, however, reabsorption is quick and an oedema diagnosis may require staining for the water channel molecule aquaporin 4 [55]. As surrogate for the possible influx of neuroactive agents immunohistochemical staining for albumin may be performed [54]

The list of histological tools could be further extended. The major diagnostic purpose, though, is to identify epileptogenic and postictal changes and to shed light on possibly epileptogenic pathologies. It rarely is the staining panel that limits the success of brain histology in clinical patients. Instead the relevant area may be easily missed. For most investigations, H.E. staining combined with Nissl's stain and GFAP will provide sufficient data for the clinician. 


\section{What the pathologist should know about the case?}

Pathological studies on epilepsy brains in animals mainly aim to identify undiagnosed seizure aetiologies, comorbidities and the substrate of drug-resistance as well as to relate clinical findings, including the focality of seizures, to morphological changes.

For a meaningful investigation, a certain data set has to be obtained from the veterinarian and/or the owner (Table 11) that clarifies predisposing factors and pedigree data, the possibility of preceding or precipitating events, possible exposure to toxins, neurological signs, phenomenology and time course of the paroxysmal disorder, MRI and EEG data, concurrent medical problems and therapy response.

Clinical data can be stratified, as Level 1 data (basic) that are mandatory and Level 2 data (detailed) that are optional. The questionnaires very much benefit from requesting as much objective and binary parameters as possible.

If not even Level 1 data can be obtained, efforts should not be wasted, since pathological findings are not able to produce and replace clinical observations. Those patients must not be included in scientific studies as neither impact nor relevance of tissue findings can be reproduced. The same holds true for acquisition of control animals. Seizure freedom has to be sought with the same stringency as seizure histories in epilepsy patients.

\section{Conclusions and outlook}

Epilepsy is a highly prevalent disease in veterinary practice that demands to be investigated using a multi- and transdisciplinary approach. Unfortunately, brain pathology has been broadly perceived as a confirmative rather than investigative tool in the retrospective work-up of epileptic companion pets. This lack of enthusiasm may be due to the paucity of tissue changes even in severe clinical presentations [56], the sometimes overwhelming severity of nonspecific ictal and postictal changes, and the elusive ambition to localise an epileptic focus in the huge brain without EEG and functional imaging data or a thorough sampling scheme.

Even though the advances in human epileptology are dominated by the activities on focal epilepsy, we may profit from the experiences in those cases and from paradigms that were brought to light by studies in rodents. In fact, natural epilepsy in dogs and cats resembles an ideal playground to test hypotheses originating from "mice and men". Comparative neuropathological concepts, indeed, have unravelled important pathobiological data that may impact on the clinical management and prognostic considerations of epileptic animals [13, 14].

It remains to be seen that in animals advances in EEG, functional imaging and brain surgery will translate into surgical removal of epileptogenic brain tissue, other than lesionectomy [1]. Until then we should benefit from the availability of post-mortem brains the offer a precious opportunity to study anatomical, neurochemical and molecular determinants for seizure progression and drug resistance, if the tissue has been stored and processed accurately and changes, on high resolution, can be attributed to specific functional brain regions. By application of the procedures illustrated herein the caseload of epilepsies of unknown cause may be further narrowed $[57,58]$.

Most hitherto published tissue studies in dogs and cats, however, underscore even baseline neuroanatomical accuracy and lack reproducible sampling schemes. That way, the relevance of published findings for a larger population of epileptic animals remains obscure, at best.

Even if the investigations may be high pitched and restricted to specialised laboratories, accurate sampling of epileptic brains can be performed at virtually any place with minimal training requirements. The true impact of the studies, on the other hand, very much depends on these, less appreciated early investigational steps.

Since the mission of this group is to foster diagnosis, research and clinical care of epilepsy in companion animals, this paper aims to ensure efficient brain sampling by pathologists and neurologists. The above described guideline rather has been tested in untrained staff and rapidly can be implemented into every pathology laboratory that wishes to contribute to the alliance against epilepsy.

\section{Additional file}

Additional file 1: Video featuring a real time demonstration of systematic brain trimming. Please note, that other approaches may be necessary for distinct lesions and neurological signs.

\section{Abbreviations}

AN: Amygdaloid nucleus; Ansi: Ansiform lobule; Aqu: Mesencephalic aqueduct; ARAS: Ascending reticular activating system; BA: Basilar artery; CA: Cornu ammonis; CC: Caudal colliculus; CCG: Caudal composite gyrus; Cing: Cingulate gyrus; Cla: Claustrum; CN: Caudate nucleus; CN-III/-VI/VII: Cranial nerves IIININII; CNS: Central nervous system; CoCa: Corpus callosum; Cru: Crura cerebri; CruS: Cruciate sulcus; Cul: Culmen; CV: Caudal vertex; DM: Dura mater; DNA: Deoxyribonucleic acid; EEG: Electroencephalography; ERC: Entorhinal cortex; FFPE: Formalin-fixed paraffin embedded; FISS: Fissures, interfoliar spaces, sulci; FisP: Primary fissure; Fol: Folium; Forn: Fornix; GFAP: Glial fibrillary acidic protein; HC: Hippocampal commissure; HE: Haematoxylin eosin; HOR: Horizontal section;

HS: Hippocampal sclerosis; IC: Internal capsule; IF: Intercrural fossa; ILAE: International League Against Epilepsy; InsC: Insular cortex; IVETF: International Veterinary Epilepsy Task Force; LGN: Lateral geniculate nucleus; LoLa: Lateral lobule; LRS: Lateral rhinal sulcus; Mam: Mammillary bodies; MAP: Microtubule-associated protein; MCA: Middle cerebral artery; MRI: Magnetic resonance imaging; OB: Olfactory bulb; Ob: Obex; OC: Optic chiasm; PAG: Periaqueductal gray matter; Para: Paraflocculus; ParaH: Parahippocampal gyrus; PeRC: Perirhinal cortex; OV: Occipital vertex; PiLo: Piriform lobe; Pit: Pituitary stalk; PL: Pathological lesion; PoRC: Postrhinal cortex; PPC: Prepiriform cortex; PraeCG: Praecruciate gyrus; ProG: Prorean gyrus; ProS: Prorean sulcus; PSS: Presylvian sulcus; Pyr: Pyramis; RC: Rostral colliculus; RP: Rostral peduncle; SAG: Sagittal section; SN: Spetal nuclei; SO: Stria olfactoria; SOB: Supraoccipital bone; SplG: Splenial gyrus; 
SUDEP: Sudden Unexpected Death in Epilepsy; TB: Trimmed brain; TFOP: Transverse fibres of pons; Thal: Thalamus; TILT: Tilted section; TO: Tuberculum olfactorium; Tra: Trapezoid body; TS: Transverse section; Tub: Tuber; TVB: Temporoventral body; UB: Unfixed brain; Uv: Uvula; Verm: Vermis; VC: Visual cortex.

\section{Competing interests}

Following reimbursements, fees and funding have been received by the authors in the last three years and have been declared in the competing interest section. CR, RGF, HAV, KM, MP and JP have received fees for acting as a consultant for Boehringer Ingelheim (KM, MP: consultancy during development and approval of imepitoin; CR: pain consultancy; RGF, JP, HAV: consultancy pre and post launch of imepitoin). AT has been an advisor for Boehringer Ingelheim. SFMB, HAV and AT have been responsible principal investigator of several research studies concerning imepitoin financed by Boehringer Ingelheim. SFMB, HAV, JP, HP, MB, CR and AF received speaking fees from Boehringer Ingelheim. HP received consulting and speaking fees and funding for a collaborative project from Eisai Co. LTD. HAV received funding for a collaborative project from Desitin and Nestlé Purina Research. AF and LDR received reimbursements from Boehringer Ingelheim. LDR has received consulting and speaking fees from Vetoquinol. MP has received consultant fees for Aratana. The other authors declared that they have no competing interests.

\section{Authors' contributions}

KM chaired the neuropathology working group (KMat, MPB, MR, FFF, AF, EW) together with MPB and wrote the first draft of the consensus paper. MPB, $M R, F F F, A F, E W$ and HAV contributed essentially to the final draft. Reproducibility and reliability of the protocol were evaluated in laboratory practice by KMat, MPB, MR, FFF and EW. HAV chaired the IVETF. All other authors have read, critiqued, commented and approved the final manuscript.

\section{Authors' information}

Corresponding author and chair of neuropathology working group: Kaspar Matiasek, Section of Clinical \& Comparative Neuropathology, Centre for Clinical Veterinary Medicine, Ludwig-Maximillians-University, Veterinärstr. 13, 80539 Munich, Germany.

Co-chair of neuropathology working group: Martí Pumarola Batlle,

Department of Animal Medicine and Surgery, Veterinary Faculty, Universitat Autònoma de Barcelona, Campus UAB, Bellaterra, 08193 Barcelona, Spain. Other members of the neuropathology working group

Chair of IVETF: Holger A Volk, Department of Clinical Science and Services, Royal Veterinary College, Hatfield, Hertfordshire, UK.

All other co-authors are members of IVETF, are list alphabetically and have approved the consensus statements.

\section{Acknowledgements}

This paper implements mutual experiences in epilepsy pathology collected by esteemed colleagues and coworkers. Many of the concepts have been based on comparative algorithms that Prof. Erwin Dahme, LMU Munich, addressed already fourty years ago. Individual approaches however would not have been intertwined to this systematic work-up without the groundbreaking efforts to clarify and standardise epilepsy pathology in humans by Prof. Ingmar Blümcke, German Epilepsy Registry and the Neuropathological Institute, University of Erlangen. The authors also would like to thank the research office for assessing the manuscript according to the Royal Veterinary College's code of good research practice (Authorisation Number - CCS_ 01029). The authors are grateful to all owners of epileptic pets and veterinary colleagues who have inspired the group to create consensus statements. This study was not financially supported by any organization or grant.

\section{Author details}

'Section of Clinical and Comparative Neuropathology, Centre for Clinical Veterinary Medicine, Ludwig-Maximilians-University, Veterinärstr. 13, 80539 Munich, Germany. ${ }^{2}$ Department of Animal Medicine and Surgery, Veterinary Faculty, Universitat Autònoma de Barcelona, Campus UAB Bellaterra, 08193 Barcelona, Spain. ${ }^{3}$ Department of Animal and Clinical Sciences, Faculty of Health and Medical Sciences, University of Copenhagen, Frederiksberg C, Denmark. ${ }^{4}$ Department of Small Animal Medicine and Clinical Biology, Faculty of Veterinary Medicine, Ghent University, Salisburylaan 133,
Merelbeke 9820, Belgium. ${ }^{5}$ Animal Health Trust, Lanwades Park, Kentford, Newmarket CB8 7UUSuffolk, UK. ${ }^{6}$ Fernside Veterinary Centre, 205 Shenley Road, Borehamwood SG9 0THHertfordshire, UK. ${ }^{7}$ University of Melbourne, 250 Princes Highway, Weibee 3015VIC, Australia. ${ }^{8}$ North Carolina State University, 1052 William Moore Drive, Raleigh, NC 27607, USA. ${ }^{9}$ University of Minnesota College of Veterinary Medicine, D426 Veterinary Medical Center, 1352 Boyd Avenue, St. Paul, MN 55108, USA. ${ }^{10}$ Clinical Unit of Internal Medicine Small Animals, University of Veterinary Medicine, Veterinärplatz 1 , 1210 Vienna, Austria. " Vet Extra Neurology, Broadleys Veterinary Hospital, Craig Leith Road, Stirling FK7 7LEStirlingshire, UK. ${ }^{12}$ College of Veterinary Medicine, University of Georgia, 501 DW Brooks Drive, Athens, GA 30602, USA. ${ }^{13}$ Chicago Veterinary Neurology and Neurosurgery, 3123 N. Clybourn Avenue, Chicago, IL 60618, USA. ${ }^{14}$ Department of Pharmacology, Toxicology and Pharmacy, Ludwig-Maximillians-University, Königinstr. 16, 80539 Munich, Germany. ${ }^{15}$ Fitzpatrick Referrals, Halfway Lane, Eashing, Godalming GU7 2QQSurrey, UK. ${ }^{16}$ School of Veterinary Medicine, Faculty of Health and Medical Sciences, University of Surrey, Guildford GU2 7TESurrey, UK. ${ }^{17}$ Department of Small Animal Medicine and Surgery, University of Veterinary Medicine Hannover, Bünteweg 9, 30559 Hannover, Germany. ${ }^{18}$ Department of Clinical Science and Services, Royal Veterinary College, Hatfield AL9 7TAHertfordshire, UK.

Received: 5 June 2015 Accepted: 29 June 2015

Published online: 28 August 2015

\section{References}

1. Shihab N, Summers BA, Benigni L, McEvoy AW, Volk HA. Novel approach to temporal lobectomy for removal of a cavernous hemangioma in a dog. Vet Surg. 2014;43(7):877-81.

2. Urbach H. The Term "Epileptogenic Lesion" and How to Use it. In: Urbach H, editor. MRI in Epilepsy. Heidelberg: Springer Berlin; 2013. p. 21-3.

3. Wolf M, Bruehschwein A, Sauter-Louis C, Sewell AC, Fischer A. An inherited episodic head tremor syndrome in Doberman pinscher dogs. Mov Disord. 2011;26(13):2381-6.

4. Packer RM, Berendt M, Bhatti S, Charalambous M, Cizinauskas S, De Risio L, et al. Inter-observer agreement of canine and feline paroxysmal event semiology and classification by veterinary neurology specialists and non-specialists. BMC Vet Res. 2015;11(1):39.

5. Seneviratne U, Cook M, D'Souza W. Focal abnormalities in idiopathic generalized epilepsy: a critical review of the literature. Epilepsia. 2014;55(8):1157-69.

6. Pakozdy A, Gruber A, Kneissl S, Leschnik M, Halasz P, Thalhammer JG. Complex partial cluster seizures in cats with orofacial involvement. J Feline Med Surg. 2011;13(10):687-93.

7. Lomoio S, Necchi D, Mares V, Scherini E. A single episode of neonatal seizures alters the cerebellum of immature rats. Epilepsy Res. 2011;93(1):17-24.

8. Jokinen TS, Metsahonkala L, Bergamasco L, Viitmaa R, Syrja P, Lohi H, et al. Benign familial juvenile epilepsy in Lagotto Romagnolo dogs. J Veterinary Internal Medicine / American College of Veterinary Internal Medicine. 2007:21(3):464-71.

9. Manford M, Fish DR, Shorvon SD. An analysis of clinical seizure patterns and their localizing value in frontal and temporal lobe epilepsies. Brain. 1996;119(Pt 1):17-40.

10. O'Muircheartaigh J, Richardson MP. Epilepsy and the frontal lobes. Cortex. 2012:48(2):144-55.

11. Toyoda I, Bower MR, Leyva F, Buckmaster PS. Early activation of ventral hippocampus and subiculum during spontaneous seizures in a rat model of temporal lobe epilepsy. J Neurosci. 2013;33(27):11100-15.

12. Cavazos JE, Das I, Sutula TP. Neuronal loss induced in limbic pathways by kindling: evidence for induction of hippocampal sclerosis by repeated brief seizures. J Neurosci. 1994;14(5 Pt 2):3106-21.

13. Wagner E, Rosati M, Molin J, Foitzik U, Wahle AM, Fischer A, et al. Hippocampal Sclerosis in Feline Epilepsy. Brain Pathology. 2014.

14. Klang A, Schmidt P, Kneissl S, Bago Z, Vincent A, Lang B, et al. lgG and complement deposition and neuronal loss in cats and humans with epilepsy and voltage-gated potassium channel complex antibodies. J Neuropathol Exp Neurol. 2014;73(5):403-13.

15. Pakozdy A, Halasz P, Klang A, Bauer J, Leschnik M, Tichy A, et al. Suspected limbic encephalitis and seizure in cats associated with voltage-gated potassium channel (VGKC) complex antibody. J Veterinary Internal Medicine/ American College of Veterinary Internal Medicine. 2013;27(1):212-4. 
16. Thom M. Review: Hippocampal sclerosis in epilepsy: a neuropathology review. Neuropathol Appl Neurobiol. 2014;40(5):520-43.

17. Blumcke I, Thom M, Aronica E, Armstrong DD, Bartolomei F, Bernasconi A, et al. International consensus classification of hippocampal sclerosis in temporal lobe epilepsy: a Task Force report from the ILAE Commission on Diagnostic Methods. Epilepsia. 2013;54(7):1315-29.

18. Milne ME, Anderson GA, Chow KE, O'Brien TJ, Moffat BA, Long SN. Description of technique and lower reference limit for magnetic resonance imaging of hippocampal volumetry in dogs. Am J Vet Res. 2013;74(2):224-31.

19. Kuwabara T, Hasegawa D, Kobayashi M, Fujita M, Orima H. Clinical magnetic resonance volumetry of the hippocampus in 58 epileptic dogs. Vet Radiol Ultrasound. 2010;51(5):485-90.

20. Hudson LP, Munoz DG, Miller L, McLachlan RS, Girvin JP, Blume WT. Amygdaloid sclerosis in temporal lobe epilepsy. Ann Neurol. 1993;33(6):622-31.

21. Lahl R, Villagran R, Teixera W. Neuropathology of focal epilepsies. John Libbey Eurotext. 2003.

22. Cheong JY, Wong C, Bleasel A, Varikatt W, Ng T, Dexter MA. Late onset Rasmussen's encephalitis with triple pathology. J Clin Neurosci. 2009;16(12):1677-81.

23. Auer RN, Kalimo H, Olsson Y, Siesjo BK. The temporal evolution of hypoglycemic brain damage. II. Light- and electron-microscopic findings in the hippocampal gyrus and subiculum of the rat. Acta Neuropathol. 1985;67(1-2):25-36.

24. Potschka H, Fischer A, von Ruden EL, Hulsmeyer V, Baumgartner W. Canine epilepsy as a translational model? Epilepsia. 2013;54(4):571-9.

25. Singer M. The brain of the dog in section. Philadelphia: Saunders; 1962.

26. Reinoso-Suárez F. Topographischer Hirnatlas der Katze für experimentalphysiologische Untersuchungen. E. Merck AG: Darmstadt; 1961.

27. Pakozdy A, Angerer C, Klang A, Konig EH, Probst A. Gyration of the Feline Brain: Localization, Terminology and Variability. Anatomia, Histologia, Embryologia. 2014

28. Gil VA. Functional neuroanatomy of the dog. Bellaterra: Universitat Autònoma de Barcelona; 2012

29. Kornegay JN, Oliver Jr JE, Gorgacz EJ. Clinicopathologic features of brain herniation in animals. J Am Vet Med Assoc. 1983;182(10):1111-6.

30. Masuo Y, Imai T, Shibato J, Hirano M, Jones OA, Maguire ML, et al. Omic analyses unravels global molecular changes in the brain and liver of a rat model for chronic Sake (Japanese alcoholic beverage) intake. Electrophoresis. 2009;30(8):1259-75.

31. Bando SY, Alegro MC, Amaro Jr E, Silva AV, Castro LH, Wen HT, et al. Hippocampal CA3 transcriptome signature correlates with initial precipitating injury in refractory mesial temporal lobe epilepsy. PLOS ONE. 2011;6(10):e26268

32. Thom M. Neuropathology of Epilepsy. In: Rugg-Gunn F, Smalls J, editors. From Membranes to Mankind - A Practical Guide to Epilepsy. 14th ed. London: Epilepsy Society; 2013. p. 27-50.

33. Katelaris A, Kencian J, Duflou J, Hilton JM. Brains at necropsy: to fix or not to fix? J Clin Pathol. 1994:47(8):718-20.

34. Adamec RE, Stark-Adamec C. Partial kindling and emotional bias in the cat lasting aftereffects of partial kindling of the ventral hippocampus. I. Behavioral changes. Behav Neural Biol. 1983;38(2):205-22.

35. Adamec RE. Partial kindling and behavioral pathologies. Int Rev Neurobiol. 2001;45:409-34.

36. Adamec R. Behavioral and epileptic determinants of predatory attack behavior in the cat. The Canadian J Neurological Sciences Le J Canadien des Sciences Neurologiques. 1975:2(4):457-66.

37. Sasaki M, Tohyama K, Matsunaga S, Nakamura M, Tomizawa N, Inoue T, et al. MRI identification of dorsal hippocampus homologue in human brain. Neuroreport. 2004;15(14):2173-6.

38. Witter MP, Groenewegen HJ. Laminar origin and septotemporal distribution of entorhinal and perirhinal projections to the hippocampus in the cat. J Comp Neurol. 1984:224(3):371-85.

39. Woznicka A, Kosmal A. Cytoarchitecture of the canine perirhinal and postrhinal cortex. Acta Neurobiol Exp. 2003;63(3):197-209.

40. Kowalska DM, Kusmierek P, Kosmal A, Mishkin M. Neither perirhinal/ entorhinal nor hippocampal lesions impair short-term auditory recognition memory in dogs. Neuroscience. 2001;104(4):965-78.

41. Margerison JH, Corsellis JA. Epilepsy and the temporal lobes. A clinical, electroencephalographic and neuropathological study of the brain in epilepsy, with particular reference to the temporal lobes. Brain. 1966;89(3):499-530.

42. Crooks R, Mitchell T, Thom M. Patterns of cerebellar atrophy in patients with chronic epilepsy: a quantitative neuropathological study. Epilepsy Res. 2000;41(1):63-73.

43. Baiker K, Hofmann S, Fischer A, Godde T, Medl S, Schmahl W, et al. Leigh-like subacute necrotising encephalopathy in Yorkshire Terriers: neuropathological characterisation, respiratory chain activities and mitochondrial DNA. Acta Neuropathol. 2009;118(5):697-709.

44. Fischer M, Hossmann KA. No-reflow after cardiac arrest. Intensive Care Med. 1995;21(2):132-41.

45. Oehmichen M, Auer RN, König HG. Methods in Forensic Neuropathology. In: Oehmichen M, editor. Forensic Neuropathology and Associated Neurology. Berlin: Springer; 2006. p. 83-94

46. Jeans A, Esiri M. Brain histology. Pract Neurol. 2008:8(5):303-10.

47. Blumcke I, Thom M, Aronica E, Armstrong DD, Vinters HV, Palmini A, et al. The clinicopathologic spectrum of focal cortical dysplasias: a consensus classification proposed by an ad hoc Task Force of the ILAE Diagnostic Methods Commission. Epilepsia. 2011;52(1):158-74.

48. Pitkanen A, Nissinen J, Nairismagi J, Lukasiuk K, Grohn OH, Miettinen R, et al. Progression of neuronal damage after status epilepticus and during spontaneous seizures in a rat model of temporal lobe epilepsy. Prog Brain Res. 2002;135:67-83.

49. Wang L, Liu YH, Huang YG, Chen LW. Time-course of neuronal death in the mouse pilocarpine model of chronic epilepsy using Fluoro-Jade C staining. Brain Res. 2008;1241:157-67.

50. Kobow K, Auvin S, Jensen F, Loscher W, Mody I, Potschka H, et al. Finding a better drug for epilepsy: antiepileptogenesis targets. Epilepsia. 2012;53(11):1868-76

51. Ahmed Z, Shaw G, Sharma VP, Yang C, McGowan E, Dickson DW. Actinbinding proteins coronin-1a and IBA-1 are effective microglial markers for immunohistochemistry. J Histochem Cytochem. 2007:55(7):687-700.

52. Hwang IK, Lee CH, Li H, Yoo KY, Choi JH, Kim DW, et al. Comparison of ionized calcium-binding adapter molecule 1 immunoreactivity of the hippocampal dentate gyrus and CA1 region in adult and aged dogs. Neurochem Res. 2008;33(7):1309-15

53. Park ES, Uchida $\mathrm{K}$, Nakayama $\mathrm{H}$. Establishment of a rat model for canine necrotizing meningoencephalitis (NME). Vet Pathol. 2014;51(6):1151-64.

54. van Vliet EA, Aronica E, Gorter JA. Blood-brain barrier dysfunction, seizures and epilepsy. Seminars in cell \& Developmental biology. 2014.

55. Isoardo G, Morra I, Chiarle G, Audrito V, Deaglio S, Melcarne A, et al. Different aquaporin-4 expression in glioblastoma multiforme patients with and without seizures. Mol Med. 2012;18:1147-51.

56. Buckmaster PS, Smith MO, Buckmaster CL, LeCouteur RA, Dudeck FE. Absence of temporal lobe pathology in dogs with medically intractable epilepsy. J Veterinary Internal Medicine / American College of Veterinary Internal Medicine. 2002;16(1):95-9.

57. Schriefl S, Steinberg TA, Matiasek K, Ossig A, Fenske N, Fischer A. Etiologic classification of seizures, signalment, clinical signs, and outcome in cats with seizure disorders: 91 cases (2000-2004). J Am Vet Med Assoc. 2008;233(10):1591-7.

58. Wahle AM, Bruhschwein A, Matiasek K, Putschbach K, Wagner E, Mueller RS, et al. Clinical characterization of epilepsy of unknown cause in cats. J Veterinary Internal Medicine / American College of Veterinary Internal Medicine. 2014:28(1):182-8.

59. Lüders HO, Awad I. Conceptional considerations. In: Lüders HO, editor Epilepsy Surgery. New York: Raven; 1992. p. 51-62. 